



\title{
THE YEAST=LIKE FUNGI OF THE HUMAN INTESTINAL TRACT
}

BY

HARRY WARREN ANDERSON

A. B. Wabash College, 1907

M. A. Wabash College, 1910

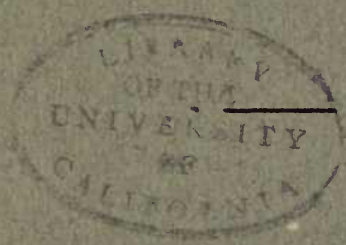

THESIS

Submitted in Partial Fulfilment of the Requirements for the

Degree of

\section{DOCTOR OF PHILOSOPHY}

IN BOTANY

\author{
IN \\ THE GRADUATE SCHOOL \\ OF THE \\ UNIVERSITY OF ILLINOIS \\ 1917
}





\title{
THE YEAST=LIKE FUNGI OF THE HUMAN INTESTINAL TRACT
}

\author{
BY
}

HARRY WARREN ANDERSON

A. B. Wabash College, 1907

M. A. Wabash College, 1910

THESIS

Submitted in Partial Fulfilment of the Requirements for the

Degree of

DOCTOR OF PHILOSOPHY

IN BOTANY

IN

THE GRADUATE SCHOOL

OF THE

UNIVERSITY OF ILLINOIS

1917 


$$
\begin{gathered}
\text { 2RI55 } \\
\text { AlOLGY } \\
\text { LIBRARY } \\
\text { LBG }
\end{gathered}
$$

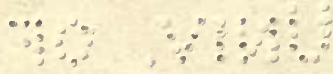

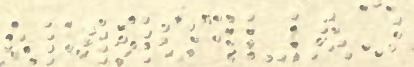




\section{TABLE OF CONTENTS}

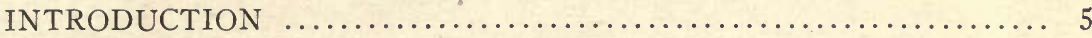

Historical ........................................ 6

INVESTIGATION OF YEASTS IN THE HUMAN DIGESTIVE

TRACT OBTAINED FROM THE FECES ................... 7

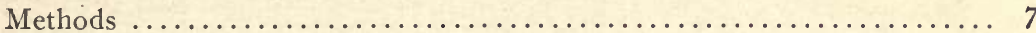

Mediums for isolation.... .......................... 7

Collecting and plating samples...................... 8

Summary of isolations of yeasts from 175 persons examined (Table 1) 9

Discussion of results................................ 9

MORPHOLOGIC, PHYSIOLOGIC, AND CULTURAL STUDIES OF

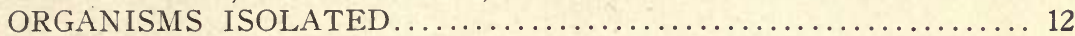

List of fungi used for comparative study (Table 2) ............. 13

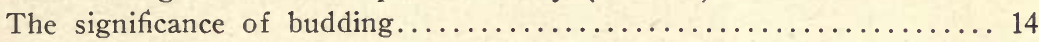

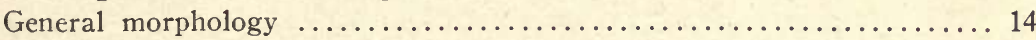

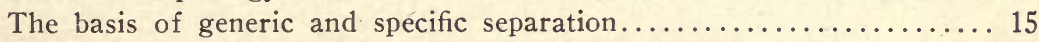

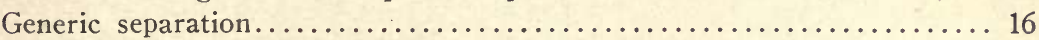

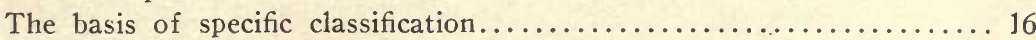

Mediums employed for specific differentiation................... 19

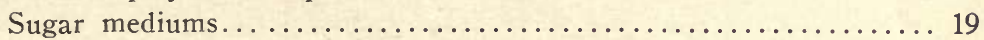

Litmus milk....................................... 20

Gelatin mediums.................................... 20

Sugar free mediums................................ 21

Pellicles, rings and grease films........................ 21

Solid mediums..................................... 21

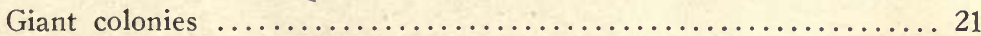

SPECIAL STUDY OF TWENTY REPRESENTATIVE ORGANISMS. 22

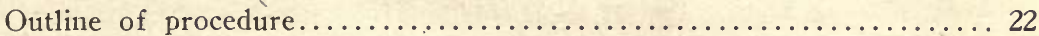

Important cultural and physiologic characteristics of twenty species

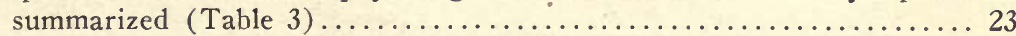

Production of acidity and alkalinity in liquid mediums........... 25

COMPARISON OF THE YEASTS ISOLATED FROM THE DIGESTIVE TRACT WITH DETERMINED PATHOGENIC AND NON-

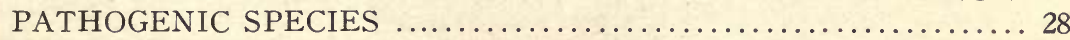

FEEDING EXPERIMENTS WITH YEASTS................ 30

THE CLȦSSIFICATION OF THE BUDDING FUNGI........... 33

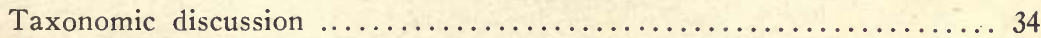

Key to the genera of budding fungi........................ 40

DESCRIPTION OF NEW SPECIES OF YEASTS............... 41

SUMMARY AND CONCLUSIONS ........................ 45

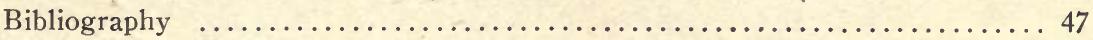

Explanation of plates........................ 52, 54, 56, 58, 60 



\title{
YEAST-LIKE FUNGI OF THE HUMAN INTES- TINAL TRACT *
}

Plates 3-8

\author{
HARRY WARREN ANDERSON
}

From the Department of Plant Pathology of the University of Illinois, Urbana

\section{INTRODUCTION}

The fungi as contrasted with the bacteria are relatively unimportant in animal pathology. However, some of the earliest attempts to associate micro-organisms with disease resulted in the discovery of fungi as their causal agents. The fungi causing thrush and ringworm were known and well described before any of the pathogenic bacteria had been isolated. During the last quarter of the 19th century the bacterial diseases have taken much of the time of students of human pathology and it has been only during the last 15 or 20 years that they have again turned their attention to the less important fungous diseases. Interest has been centered largely in those diseases grouped under the general name blastomycoses, so called because the organisms concerned have, at some stage in their life history, budding vegetative cells.

The budding or yeast-like fungi have been so constantly associated with various diseases within recent years and so much confusion exists concerning their life histories and proper botanical position, that it has been thought worth while to make a special study of these organisms from a mycologic standpoint. It was first considered essential to ascertain whether or not the budding fungi were present in the human body, their relative abundance under normal and abnormal conditions and their relation to each other and to the pathogenic blastomycetes isolated by other investigators.

The objects of the present investigation were therefore:

1. To determine the presence or absence and the relative abundance of yeast-like fungi in the normal alimentary tract.

2. To compare the number and kinds isolated from the normal alimentary tract with those found in persons suffering from gastrointestinal disturbances.

* Received for publication May 24, 1917. 
3. To determine the proper botanic position of these yeast-like organisms and to compare them with the pathogenic fungi of similar structure.

4. To investigate the mode of development and the life histories of the fungi secured.

5. To devise a practical scheme of separating species within the group.

6. To determine the fate of yeast-like organisms when ingested.

\section{Historical Review}

A brief review of some of the more recent fundamental articles on pathogenic yeasts* is all that will be attempted at this point. The earlier works have beẹn thoroughly reviewed by Plaut ('03a), Busse ('03), Gedoelst ('02), Guéguen ('04), and Guilliermond ('12), all of whom give excellent bibliographies. Emig ('16) also gives a fairly complete bibliography and reviews some of the more recent publications. Those publications dealing with the taxonomic, physiologic, cultural, and morphologic phases of the subject will be reviewed under the discussion of these items.

Recently Ashford ('15a,b, c) in studying the etiology of sprue, has announced the constant presence of a yeast-like organism in the digestive tract, thus confirming and extending the investigations of Bahr ('14), Kohlbrugge ('01), Le Dantec ('08), and Castellani ('14), all of whom had previously isolated fungi of the Oidium albicans type from sprue patients. This disease is present in the southern United States according to Wood ('15), and is of considerable importance in our tropical island territories. It has been suggested by Wood and others that pellagra, having many symptoms in common with sprue, may be caused by a similar organism.

A series of articles by Castellani ('11, '12, '13,'14), Castellani and Low ('13), and Castellani and Chalmers ('13), on the presence of yeast-like organisms of the Oidium albicans type in a number of tropical diseases has emphasized the importance of a more intensive study of these fungi. Castellani has recorded the presence of 33 species of Monilia as occurring in widely different types of disease. He has also separated the common thrush organism, formerly called Oidium albicans, into a number of new species (Castellani '16); on the basis of certain cultural and biochemical reactions.

Recently Simon ('17) has studied an infection of the lungs, of a tuberculous nature, in which he found a yeast-like organism similar to Oidium albicans. Birch-Hirchfeld ('75) has recorded a case of the thrush organism involving the lungs, and Castellani ('13) recorded 16 of his species as occurring in bronchooidiosis. Other investigators have also recorded cases where the thrush fungus was present in the lungs.

The work of Gilchrist and Stokes ('98), Ricketts ('01), Stober ('14), Wade and. Bel ('16), and others on blastomycosis in this country will be reviewed in greater detail in another section.

Casagrandi ('98) has made the most complete study of the yeast-like fungi of the alimentary tract. He came to the conclusion that: "(1) In the intes-

\footnotetext{
* The term yeasts will be employed in the following pages when referring to the yeastlike organisms under consideration. This shorter term does not imply that the fungi referred to are true yeasts in the narrower sense of the term.
} 
tines of the healthy children there were as many blastomycetes as in those affected with diarrhea; (2) The forms found in both conditions vary from case to case and it cannot be maintained as many wish, that they always belong to Saccharomyces cerevisiae, Saccharomyces ellipsoideus, etc.; (3) The blastomycetes must, for the present, be regarded as accidental ingredients of the feces, since in the same case observed at different periods they vary so extraordinarily, and since in no case has any one succeeded in discovering a definite form, whether in man or other animals, when these were affected with diarrhea; (4) Up to the present time it has not been possible to bring forward any evidence which will go to show whether the yeasts present in the intestines have any useful or harmful action on the gastro-intestinal functions."

Ashford ('16) has made an extensive study of animal inoculation with his sprue organism both by injection and ingestion. He explains his own negative results in his feeding experiments at an earlier date on the ground that the organism concerned rapidly loses its virulence when kept on artificial laboratory mediums. His positive results were obtained by the use of recently isolated yeasts or those passed through susceptible animals.

\section{INVESTIGATION OF YEASTS IN THE HUMAN DIGESTIVE TRACT OBTAINED FROM THE FECES}

The series of experiments which follows was planned to determine the presence or absence and relative number of yeast-like organisms in the human alimentary tract, and to discover any relation which might exist between their presence and gastro-intestinal disturbances of various kinds. They were intended to extend and supplement the investigations of Ashford and others. In addition, it was hoped that a study of such organisms as were isolated would furnish a means of distinguishing the pathogenic yeasts from those harmless ones accidentally present but frequently occurring in the feces.

\section{METHODS}

Mediums for Isolation.-The fact that the feces contain such a large number of bacteria, as compared with the fungi, has made the isolation of the latter group very difficult when using the ordinary culture mediums and standard plating methods. For this reason, a medium which restricted the growth of the bacteria had to be employed. The most useful medium for this purpose is undoubtedly Sabouraud's agar, as suggested by Ashford ('15c). Since the method of preparation has been somewhat modified and since the standard textbooks on bacteriologic methods do not include the formula for this valuable medium the following account is included:

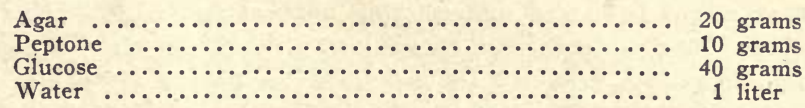

The agar, peptone, and water are mixed and dissolved in the usual way. The medium is then titrated and rendered +2 acid with normal hydrochloric acid. Without further heating, the sugar is added and the medium tubed in previously sterilized tubes. Care is necessary in sterilizing since the high acidity of the 
medium may prevent solidification. Ten minutes at 5 pounds pressure is usually sufficient. This is better than discontinuous sterilization, since reheating the agar seems to destroy its power of solidifying under these conditions. The high acidity of the medium prevents the bacteria of the feces from developing rapidly.

Collecting and Plating Samples.-Since yeasts are present in fairly large numbers in the air and on unsterilized objects, it was necessary to collect the samples with as little contamination as possible. For this purpose small vials, $20 \times 70 \mathrm{~mm}$., with wooden spatulas firmly fixed in the cork and extending almost to the bottom of the vial were prepared. These could be sterilized in the hot air sterilizer with the cork and spatula in place. By means of the spatula a small portion of the sample to be studied was introduced into the vial, without contact with external sources of contamination. In this condition the vial could be shipped some distance without danger of contamination and with little change in the water content of the sample.

The regular dilution and poured plate method was found unsatisfactory for the primary cultivation of the yeasts and their separation from the bacteria. This was probably due to the fact that the yeasts develop rapidly only on the surface of the plate and few are left on the surface under these conditions. Another method was therefore employed in most of the isolations. This is a modification of the method used by Ashford.

Three plates of the acid glucose agar were poured and allowed to harden. A stiff platinum needle was then sterilized and thrust into the sample. The agar was touched lightly at points about $4 \mathrm{~mm}$. apart in a line across the plate. This process was repeated, each series of contacts forming a row across the plate, 10-20 contacts being the usual number in each row. There were usually about 20 rows on each plate, thus giving 200-400 contacts. This procedure was modified somewhat when a large or very small number of yeasts was expected, or where the consistence of the feces made a change necessary.

While no exact quantitative results were expected by the use of this method some interesting comparative results were obtained. A sample which contained a relatively large number of yeasts would develop 20-200 yeast colonies on each plate, while in those in which only the normal number was present, only 2 or 3 colonies appeared on each plate, or 5 or 6 colonies would appear on 1 plate and none on the other two. This striking difference was especially clear in the feeding experiments where the number would jump from less than $1 \%$ of the contacts before feeding to 80 or $95 \%$ immediately after feeding, and then back again to $1 \%$ or less a few days later. The dilution method was used in a number of cases as a check on this contact method with the result that the latter was found to be even more accurate than was expected. There is no question but that it gives accurate comparative results when carefully carried out.

The yeast colonies which were developed on the medium were usually pearl-white or pink in color and could be distinguished from the usually clear bacterial colonies. However, every distinctive colony on a plate was examined in order not to overlook a possible unusual yeast growth. An objection that might be urged against this method is the possibility of yeasts existing in the feces as sensitive to acid conditions as are the bacteria. In order to test this, a large number of yeasts were obtained from various sources and each was plated on agar directly, or mixed with the feces and then plated. In no case did the yeast fail to develop. All the common species of Saccharomyces, Mycoderma, Torula, Oidium, and Cryptococcus were tried. Also undetermined yeast-like fungi from fruits, fresh yeast-cake, air, soil, stomach contents, etc., were used with like results. 
Table 1 gives a numerical summary of the results obtained from the study of samples taken from 175 persons by the methods described.

TABLE 1

Summary of Isolations of Yeasts from 175 Persons Examined

Total number of persons from whom samples were obtained $\ldots \ldots \ldots \ldots \ldots \ldots \ldots \ldots \ldots$

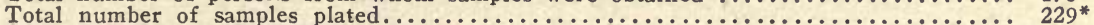

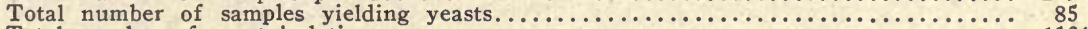

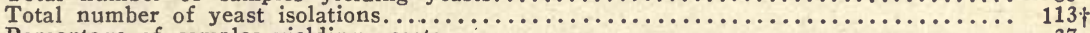

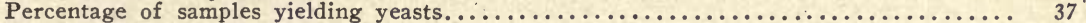

Total number of persons without gastro-intestinal disturbances................... 98

Total number of diarrheal cases (exclusive of sprue and pellagra cases) $\ldots \ldots \ldots \ldots \ldots \ldots . \ldots 31$

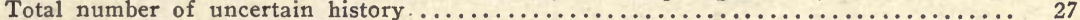

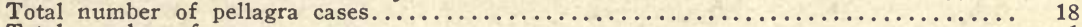

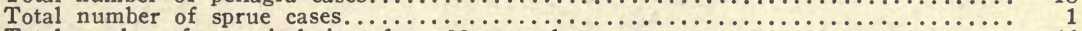

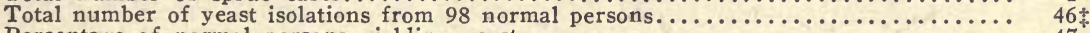

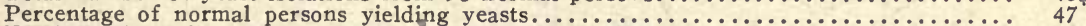

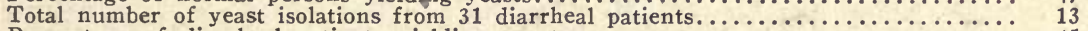

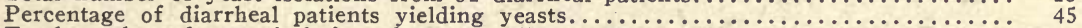

Total number of yeast isolations from 18 pellagra patients.................... 4

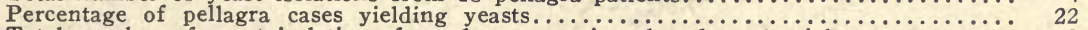

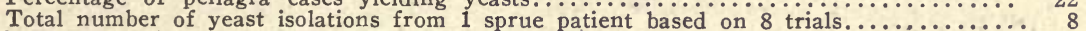

Percentage of yeast isolations in sprue patient $(8$ trials $) \ldots \ldots \ldots \ldots \ldots \ldots \ldots \ldots \ldots \ldots \ldots$

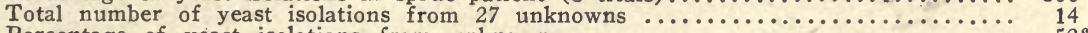

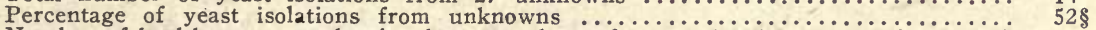

Number of healthy persons showing large numbers of yeasts ( $10 \%$ or more of contacts)

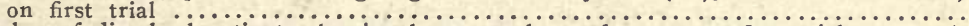

Number of diarrheal patients showing large numbers of yeasts on first trial..........

Percentage of sprue patients showing large numbers of yeasts. $\ldots \ldots \ldots \ldots \ldots \ldots \ldots \ldots$

Number of pellagra patients showing large numbers of yeasts. $\ldots \ldots \ldots \ldots \ldots \ldots \ldots \ldots$ dates.

* In several cases a number of samples were taken from the same person at different

† Two or 3 different species frequently occurred on the same plate from 1 person.

\# plate containing several species was regarded as a single isolation in this and the following results in the table.

$\S$ The high percentage here is due to the fact that some of these isolations were made by others who reported only successful results. In cases which I actually recorded the percentage approached that of the normal persons.

II Percentage results are given here since only a single case of sprue was included, but a number of trials proved the uniform presence of yeasts in the feces.

\section{DISCUSSION OF RESULTS}

The percentage of positive results recorded in Table 1 , based on the total number of isolations, is undoubtedly lower than it should be because, in a number of cases, an Oidium lactis type of fungus developed so rapidly as to prevent the growth of yeasts had they been present. In other cases, especially in diarrheal stools, certain slime-forming bacteria developed in spite of the acidity of the medium. Furthermore, the small quantity of feces used for plating would naturally reduce the number of positive results. There is little question but that yeasts are present in small numbers in practically all human feces.

The percentage of positive results from healthy persons and from those with diarrhea is approximately the same. The sprue patient, in 8 recorded trials, yielded over $50 \%$ of "colonies in every plating. Thus the fact that the results were positive in this case is not as significant as finding a very large number in every trial. The pellagra 
cases yielded less than the normal number of positive results. However, Oidium lactis was present in several of the pellagra stools and had an unusual chance to develop before plating on account of the long time in transit from the point of collection (Spartanburg, S. C.). Only 1 of the pellagra patients showed a large number of yeasts in the first trial. Failure to secure more samples from this person rendered the results incomplete.

The results of Ashford and those I recorded in a sprue patient indicate that the constant presence of large numbers of yeasts in the stools is more significant than the presence of a few in each sample. For this reason particular attention was given to those persons in whom a large number of yeasts was found in the first plating, and a special effort was made in such cases to secure samples at intervals from these same persons. It will be shown from the feeding experiments that a comparatively small amount of yeast material ingested with the food will cause a very decided increase in the number found in the feces. Therefore, the presence of a large number from 1 sample could be accounted for by the fact that the person had eaten fruit or other food containing an abundance of yeasts. If repeated trials showed a constant large number some other cause would have to be sought. In Table 1 it is seen that 9 healthy persons gave large numbers ${ }^{\bullet}$ of yeasts on the 1 st trial. Subsequent samples from these same persons showed, on the 2nd trial, only 2 giving large numbers, and on the $3 \mathrm{rd}$ trial only 1 continued to give positive results. This last case was that of a woman about 65 years old in the Kankakee State Hospital for the Insane. A record of this patient showed that she had no gastro-intestinal disorder but was in a very weak condition during the course of the trials. After the 5th positive sample had been obtained she died from a cerebral hemorrhage. She was given the ordinary diet.

Table 1 shows that none of the diarrheal patients gave large numbers of yeasts, and that in only 1 pellagra patient was there an unusual number present. These results indicate that in the sprue case the constant presence of a large number of yeasts in the feces has some special significance. From the fact that in sprue the stools are decidedly acid, and that acidity favors the development of such organisms as those found in sprue patients, one might argue that their presence is only indicative of abnormal conditions arising from other causes. Thus the thrush organism develops in the mouth of infants before the secretions render it alkaline, and a number of investigators have stated 
that the appearance of the thrush organism in the mucous membrane of adults indicates an acid condition. The presence of abundant yeasts might, therefore, be an indication of abnormal conditions in the intestinal tract. If this hypothesis were true one would expect to find large numbers of yeast-like fungi constantly-present in other types of itnestinal disorders which give similar conditions to that of sprue or thrush. The results obtained in this investigation show that comparatively few diarrheal patients yield large numbers of yeasts, and indicate that some other explanation of the large numbers found in sprue cases is necessary.

The geographic distribution of the persons studied was found to be of no particular significance. Persons from the southern states gave no different results from those in the north. A large number of samples were obtained from the Kankakee. State Hospital for the Insane. These samples were taken at different times extending over a period of several weeks, thus securing them under varying conditions of diet. The samples from pellagra cases were obtained from the United States Pellagra Hospital, at Spartanburg, S. C. A number of persons from Urbana and Champaign also furnished material for study. An epidemic of gastro-intestinal trouble at the Lincoln State School and Colony, at Lincoln, Illinois, furnished an exceptional opportunity for studying diarrheal cases. Local physicians kindly secured a number of miscellaneous cases of intestinal disturbances.

The sprue case recorded is of special interest since it is one of the few studied in temperate climates from an etiologic standpoint. The person from whom the isolations were made had lived for 2 years in Porto Rico (1912-1914) where it is supposed she contracted the disease. She then came to Urbana and has lived here since, except that the summer of 1915 was also spent in Porto Rico. The present tests were made during the fall of 1916.

As mentioned, the diet of the person could evidently influence the number of yeasts present at any one time. It was not possible, however, to make a detailed study of the diet of the persons examined and no attempt was made to control this factor except to secure samples from a large number of persons under different conditions of diet and at various seasons of the year.

Summarizing the results obtained from 175 persons, it is evident that yeast-like organisms are present only in relatively small numbers in healthy persons; that ordinary gastro-intestinal disorders have no relation to the yeast flora of the intestinal tract; that the constant presence of large numbers of yeasts is not met with in healthy or diseased persons under ordinary conditions; and that in the single sprue patient examined, a species of yeast was constantly present in large numbers in all samples plated. 
Morphologic, Physiologic, and Cultural Studies of Organisms Isolated

The 113 organisms isolated were grown on a number of mediums in order to make a preliminary separation into groups on the basis of striking differences. For comparison, the determined organisms given in Table 2 were obtained from various sources. In addition to these a number of undetermined species isolated from the gastric residua of normal persons was furnished by Mr. Max Levine of Iowa State College; organisms which are of special interest on account of their source. Several cultures of species of Mycoderma, Torula, and Monilia, indicated by number only, were received from different laboratories. Cultures isolated from different fruits during the course of this study were also used for comparison, as was also Sclerotinia (Monilia) cinerea isolated from plum. Dr. Simon also kindly sent me the organism described by him as causing a tuberculous condition of the lungs. Blastomyces dermatitidis was obtained from the Memorial Institute of Infectious Diseases in Chicago and from the American Museum of Natural History. Thus, in all, over 160 cultures were used in the preliminary study of the group of budding fungi. While only a limited number of these were studied in detail, a series of comparative observations was made on the entire series. As the result of a preliminary study the organisms isolated were separated into a number of large groups which are described.

Variation in color furnished the first basis of separation. There appeared in a large number of the original plates pink or red colonies of yeasts which made gelatinous watery growths and appeared very similar in gross characters. Isolations of these were not attempted except in about half the first samples tested, since it was early decided that most were of the same species. Whenever a variation in these pink colonies was observed, such as shade of color, type of growth, or shape of cells on microscopic examination, the form was isolated and saved for future comparison. Four types of red or pink yeasts were thus obtained which will be referred to only as Types 1-4 since this paper includes a specific study of only 1 of these.

The 2nd group, on the basis of color, included those of a chalky-white appearance on agar slant cultures. These constituted the largest percentage of yeasts isolated and it is with this group that I am now especially concerned.

The 3rd group develops a yellow, golden, or gray colony on agar plates. This is a miscellaneous group for the inclusion of all the odd forms not included in the first 2 groups. It is especially important, however, since many of the so-called pathogenic yeasts are of this type. Only 2 isolations of this type were made but several of Levine's yeasts from normal stomach contents belong here. Most of the yeasts of this type liquefy gelatin and develop more or less of a slimy growth on most mediums. These 3 groups will be designated as the 'pink', 'white', and 'golden' groups.

The white group, on account of the number of forms isolated and their similarity to most of the important pathogenic yeasts described in the literature as 'Monilia' and 'Oidium' species, were made the object of special study. This group could be subdivided into 2 very distinct subgroups: (1) those which form a slightly to decidedly heaped, glistening growth, especially in young slant cultures, and (2) those which form a spreading, dull-white growth on agar slants and usually produce a heavy, dry pellicle within 48 hours on liquid mediums. The latter type will be designated the 'Mycoderma' type since this characteristic growth is the basis of the formation of this genus according to Hansen, Will, and others. 
TABLE 2

\section{List of Fungi Used for Comparative Study}

Number

Name of fungus*

1 Saccharomyces cerevisiae ............

Saccharomyces glutinis ............

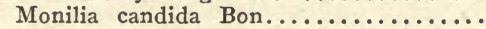

4 Monilia candida Bon...............

5 Monilia humicola Oudem............

6 Monilia sitophila (Mont.) Sacc........

7 Oidium humi Maze ...............

8 Oidium lactis Fresenius.............

9 Oidium pullans Lind..............

10 Saccharomyces hominis Busse........

11 Saccharomyces Pastorianus Hansen....

12 Saccharomyces glutinis (Fres) Cohn....

13 Saccharomyses ellipsoideus (I) Han...

14 Saccharomyces cerevisiae Hansen......

15 Saccharomyces anomalus Hansen......

16 Saccharomyces (pathogenic) Binot......

17 Saccharomyces (pathogenic) Curtis....

18 Saccharomyces (pathogenic) Foulerton..

19 Schizosaccharomyces Pombe Lindner...

20 Schizosaccharomyces octosporus Beyer.

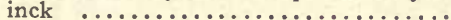

21 Torula glutinis (Conn) Pringsh. et Bi. lersky $\ldots \ldots \ldots \ldots \ldots \ldots \ldots \ldots \ldots$

22 Torula humicola Daczewska ..........

23 Torula rubra Schimon .............

24 Willia belgica Lindner............

25 Blastomyces dermatitidis Gilchrist and Stokes

26 Blastomyces dermatitidis Gilchrist and

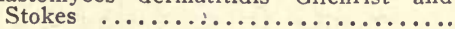

27 Oidium albicans $\mathrm{Ch}$. Robin..........

Source and Remarks

Parke Davis \& Co., Detroit

Parke Davis \& Co., Detroit

Parke Davis \& Co., Detroit

Centralstelle für Pilzkulturen, Amsterdam. Holland

Centralstelle für Pilzkulturen, Amsterdam, Holland

Centralstelle für Pilzkulturen, Amsterdam, Holland

Centralstelle für Pilzkulturen, Amsterdam, Holland

Centralstelle für Pilzkulturen, Amsterdam, Holland

Centralstelle für Pilzkulturen, Amsterdam, Holland

Centralstelle für Pilzkulturen, Amsterdam, Holland

Centralstelle für Pilzkulturen, Amsterdam, Holland

Centralstelle für Pilzkulturen, Amsterdain, Holland

Centralstelle für Pilzkulturen, Amsterdam, Holland

Centralstelle für Pilzkulturen, Amsterdain, Holland

Centralstelle für Pilzkulturen, Amsterdam, Holland

Centralstelle für Pilzkulturen, Amsterdam, Holland

Centralstelle für Pilzkulturen, Amsterdam, Holland

Centralstelle für Pilzkulturen, Amsterdam, Holland

Centralstelle für Pilzkulturen, Amsterdam, Holland

Centralstelle für Pilzkulturen, Amsterdam, Holland

Centralstelle für Pilzkulturen, Amsterdam, Holland

Centralstelle für Pilzkulturen, Amsterdam, Holland

Centralstelle für Pilzkulturen, Amsterdam, Holland

Centralstelle für Pilzkulturen, Amsterdam, Holland

American Museum of Natural History

Memorial Institute of Infectious Diseases, Chicago

London, England, H. D. Singer, Kankakee State Hospital

* The names of the fungi and the authors of the species here listed are those used by the person sending the cultures.

After the separation of the cultures on the basis of the gross characters, a morphologic study of a large number of these forms was undertaken. The criterion used in selecting these fungi from others which frequently occurred on the same plate was their 'yeast-like' appearance. By this is meant the formation in young cultures of single cells which reproduce by budding, in other words, unicellular, budding organisms. Before going into more detailed description of morphologic characters a discussion of the significance of the budding process will be given. 


\section{The Significance of Budding}

The production of a new cell or a new individual plant by budding is an entirely different process from the production of a new cell, conidium, or spore by septation or abjunction. In the budding process a protuberance is formed at some point on the parent cell. This swells and increases in size in the distal portion but not at the junction. This results in a narrow neck which remains narrow during the further growth of the cell. When the daughtcr cell has reached a certain size the protoplasm at the neck is separated and a wall is formed between the end of this cell and the portion of the original cell from which the bud arose. This results in 2 distinct and separate individuals, and the daughter cell is very easily detached from the parent. In the process of septation, on the other hand, the parent cell elongates and the protoplasm is separated by a cross wall. If the fungus has a hyphal development this usually takes place at the end of the hypha, that is, the growth is apical. If a branch is formed a protuberance appears as in a bud, but there is no constriction or only a slight constriction at the point of attachment to the parent hypha. If budding is regarded as a type of reproduction "comparable to the formation of conidia a difference may also be seen here in most cases, in that usually the end of the sporophore elongates and the conidia are cut off by septation as in the formation of a new cell. The cell which is cut off to form the conidium may enlarge, become rounded, or change its shape in various ways. In some cases a condition falsely simulating budding seems to occur, in that near the end of the elongated sporophore there appears a sinus which gradually narrowing squeezes off the spore. But in this case the conidium is from the first as broad as the parent hypha. In some of the lower hyphomycetes there are conditions of conidial formation which closely approach true budding. In these cases the resulting conidia when mature are definite in form and size, and, on germination, produce true germ tubes. In the case of the yeasts the buds are in no sense conidia or spores of the parent plant. Rather they are new individuals ready to grow and carry on all the necessary metabolic processes of the organism. On germination, conidia or spores send out true germ tubes by the further growth of which a mycelium is formed. In the budding process, on the other hand, the new cells formed, on further growth, produce new buds and not germ tubes.

It is recognized that the fungi which develop a true mycelium, such as Exoascaceae and Ustilaginales may have budding stages in their life histories. Budding is not rare in most of the larger orders of fungi, and may appear under abnormal conditions in many forms (de Bary '87). It is not maintained. on the other hand, that the yeast-like fungi described in this article never form a septate mycelium. But it is asserted that there exists a group of fungi which, under a very wide range of cultural conditions, rarely form septate hyphae, but on the contrary produce new individual, unicellular plants almost exclusively through the process of budding.

\section{General Morphology}

Microscopic examination of all the cultures revealed a wide range of morphologic characters. The only character all forms had in common was that of budding. In young cultures, in all cases, the only form was the budding yeast-like cells. These usually contained more or less distinct vacuoles, although such were frequently absent. One or more refractive granules was also evident in the vacuole or cytoplasm. In old cultures a decided change was usually evident in the structure and form of the cells. In many cases, the 
cells had elongated, and, remaining attached to each other, formed a hyphal thread constricted at the ends of the cells. These 'articles' were easily broken apart with the result that elongated cells were scattered among the shorter budding cells. In these old cultures 'giant cells', frequently' 10 times the diameter of the normal cells, were present. The cell contents also changed, usually 1 or more large 'oil' globules appearing in each cell and frequently completely filling it. In other cases no elongated or giant cells were found and the individual cells were very small and showed no budding.

The forms which these yeast-like fungi assume are various. Figure 1 represents, diagramatically, a series of forms on which the terminology in the plates is based.

The formation of a series of elongated cells does not necessarily imply that the yeast concerned has given up the budding habit in favor of hyphal formation and septation. In the majority of cases such series of cells are formed by the apical budding of each cell in turn and the subsequent elongation of the members of this series of cells. In certain species, however, and under conditions which will be explained in more detail, the cells pass over into elongated mycelial threads which form true septa (Plate 3, Fig. 13) just as in cell division in the other fungi. This condition, however, is rare and even here

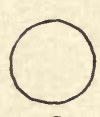

a
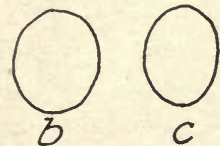

C
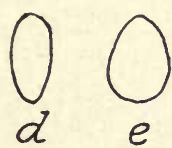

e

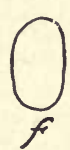

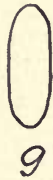
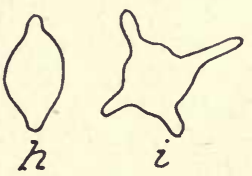

Fig. 1. Forms of Yeast-Like Fungi: a, round; b, oval; c, elliptical; d, narrowly ellip tical; e, ovate; $f$, oblong; $g$, elongated; h, limoniform apiculate; $i$, amoeboid.

the individual cells of the myceiium send out true buds, which, in turn, bud in the same manner as the cells in a young culture. A large number of species do not form septate hyphae under any condition so far discovered. There are, therefore, 3 distinct morphologic groups in the forms studied: (1) those which have only round or oval cells, (2) those which may form elongated cells but do not produce septate hyphae, and (3) those which form elongated cells which may pass over into septate hyphae. There is not a sharp distinction between the first 2 groups but these are fundamentally different from the last.

In all the forms studied, even when a septate mycelium was developed, there was never a tendency to form a dry, aerial mycelium, such as is produced by the majority of fungi when in culture. The yeasts were grown on or in a very large number of mediums under a variety of conditions as to moisture and temperature, but never was there an approach to aerial mycelial production. This is of fundamental importance in distinguishing these forms from such types as Oidium lactis, Monilia cinerea, and Blastomyces dermatitidis.

\section{The Basis of Generic and Specific Separation Within the Group}

The forms isolated from the intestinal tract, when tested for endospore formation by various standard methods, were found to be, with 2 exceptions, asporogenic species. Since the majority of pathogenic fungi and a very large number of the species of yeast-like organisms in-nature are of this type, the following discussion will deal exclusively with the asporogenic forms. Since they have no sexual or 'perfect' stage they are naturally included in Fungi imperfecti. 
Generic Separation.-In the preceding section it was stated that a distinct morphologic difference exists between the forms which never produce new cells by septation and those which may show septation under proper conditions. This fundamental difference has been recognized by a number of writers. Cao ('00), on the basis of the development of a villous growth in gelatin-stab cultures and the formation of elongated cells, wished to place all such forms in the genus Oidium. He described a large number of such fungi using numbers only to designate his 'species.' He did not distinguish between those which form elongated cells without septation and those which produce septa. - Will ('03-'08), in several instances in his articles on "Sprosspilze ohne Sporenbildung" called attention to these 2 types. Geiger ('10) also differentiates clearly between the 3 groups enumerated. He believed that the forms having septate hyphae should be placed in the genus Monilia on the ground that Monilia candida is of this type. He erects a new genus, Pseudomonilia, to include 4 species having elongated narrow cells of a hyphal nature, but without septa. The forms producing septate mycelium under certain circumstances but usually forming budding cells are included, by most authors, under either the genus Monilia or Oidium. The latter genus is, as a rule, used to designate forms of the Oidium lactis type. The species which do not form these elongated septate hyphae are usually placed in the genus Torula if they do not form a pellicle in liquid mediums, while if such is formed, they are called Mycoderma.

It is recognized that there may occur conditions under which the nonseptate might pass over into the septate type. But a series of observations on a number of forms which produce elongated cells but do not form septa tends to show that the character is constant.

We have, therefore, a group of the Fungi imperfecti which is distinguished by the fact that, with the conditions under which they grow and under all the usual conditions of laboratory culture, reproduce by budding exclusively and do not form a dry, aerial mycelium. This group in turn may be separated into 2 distinct morphologic groups on the basis of septation or nonseptation. These 2 groups should be given generic rank and such a classification is to be proposed.

The formation of elongated, radiating, thread-like filaments in gelatin-stab cultures does not prove that septate hyphae are formed. Hanging drop cultures which are allowed to develop several days are most useful in showing this character. The filaments extend from the drop, in the case of solid mediums, into the water of condensation on the cover glass, and may be examined even under an oil immersion objective. By watching these for an hour or so the formation of septa may be observed if it occurs. Various mediums may be used for hanging drop cultures but a most satisfactory one is $0.5 \%$ beerwort agar solution. A tube containing such a solution is melted and a few yeast cells on the end of a needle are introduced. The tube is then shaken and a portion drawn up into a sterile glass tube with a fine drawn end. The drops are then placed on a sterile cover glass and inverted on a ring in the usual manner.

The Basis of Specific Classification.-The basis of specific differentiation in most microscopic organisms, aside from the bacteria, is morphologic. In the fungi the character of the mycelial growth, the form, size, marking, and arrangement of the reproductive bodies, whether sexual or asexual, are used for separating genera and species. When any of these characters vary within the species, the limits of variation are not wide, and may be easily determined by biometric methods. Frequently internal structures, thickness of spore walls, 
etc., aid in the separation of species. In the yeast-like organisms under consideration there are certain difficulties encountered in attempting to separate the species by the various characters given. The yeasts are primarily unicellular organisms, even when an apparent mycelium is formed. These individual cells tend to assume a certain fairly uniform shape under a definite set of conditions (Fig. 1). When 2 species are examined side by side under the microscope it usually is easy to see that they are different. But when a number of cells of 1 of these species are measured a wide variation-is observed, and when compared with the other species these variations cause the measurements to overlap to such an extent that it is impossible to distinguish, from description, which of the 2 is under consideration. A very large number of measurements possibly would reveal a constant difference between the 2 species, but the necessary measurements would be too laborious and uncertain for practical use. It is highly desirable that a system of species differentiation be devised which is practical for the average laboratory worker.

'The difficulties of differentiating species arising from this great variation in the size and form of the cells has been recognized by such workers as Hansen, Will, and Geiger. They maintain, as I do, that the morphologic characters have little analytic value when taken alone.

An attempt was made to use internal structures such as size, number, and position of granules, the relative refraction of the protoplasm, the size, number, and location of the vacuoles, etc., as a basis for separating species. It was found, however, that these internal structures varied according to the age of the cell and the medium in which it was placed. At one stage a small vacuole with a single dancing particle within it was present; a few hours later this vacuole would be much larger and there might be several dancing particles in it, or the vacuole might seem to disappear entirely, due, probably, to the change in the refractive index of the solution. Thus no satisfactory means of separation could be found by a study of internal structure.

The form of the cells is fairly constant in some species. For example, Saccharomyces cerevisiae differs from Saccharomyces pastorianus in a constant manner, and one would have no difficulty in separating these 2 species under the microscope. But the number of possible forms the yeasts can assume is very limited, as is indicated by Figure 1. Furthermore, a single species may have cells of all of these forms in a single field of the microscope (Plate 3, Fig. 10). This is especially true of the 'wild' yeasts under consideration.

The manner of budding is constant in many species. If a given species is cultivated under a fairly wide range of conditions the buds may uniformly appear at some definite point on the cell. But here again there are only a few possibilities of differences. A large number of species may bud in the same manner and again there are forms which may vary in their manner of budding under varying conditions. The tendency to form elongated cells of a hyphal character is constant in certain species, but is present in a large number of species.

All of the characters mentioned, when used alone or in combination, are of value in the description of a species; but the general statement can be made that no constant morphologic character or combination of characters can be found which is uniformly reliable in differentiating single species, on account of the great tendency to vary among species and the limitation of possibilities in such simple organisms.

From this discussion it is evident that morphologic characters must be used in connection with biochemical properties and cultural peculiarities in the differentiation of asporogenic yeast-like species in the same manner in which the 
bacteriologist makes use of these properties. Will ('03-'15) has made an exhaustive study of the asporogenic yeasts, using biochemical properties and cultural characters as a means of differentiating the 'forms' obtained. Geiger ('10) also uses Will's methods in his study of the species of the genus Pseudomonilia. The assimilation of different sugars, alcohols and organic acids, the production of alcohol and acids, the resistance to alcohol, etc., are some of the characters determined for each form studied. Both authors also emphasize the importance of the use of 'giant colonies.'

Lutz and Guéguen ('01) have proposed a classification based on morphologic and cultural characters. They wish to establish a standard method of procedure to use with all hyphomycetes such as the bacteriologists employ for differentiating bacterial species. They recommend the employment of a synthetic medium (Raulin's solution*) with and without various sugars, the addition of other carbohydrates, glycerin, etc. They also employ milk, potato, and carrot slants and egg albumin.

The complicated procedure recommended by Will cannot be undertaken in ordinary routine work on account of the complex chemical analysis employed, and the time necessary to complete the study of a species. This is especially true where pathogenic yeasts are to be studied, since the method employed by Will requires at least 3 months for complete observation. The procedure recommended by Lutz and Guéguen has much in its favor, but does not include several of the most important differentiating mediums. The yeast water employed by Will and others is more satisfactory as a basic solution although its chemical composition is not as definite as that of the synthetic medium of Raulin.

Variations in cultural and physiologic characters are encountered in the yeasts, even to a greater extent than in the bacteria. This is especially true in streak cultures on solid mediums such as agars, carrot and potato slants. Variation in fermentation of sugars and in acid-production is also frequently encountered. Ashford ('15d) has recorded the fermentation of galactose and sucrose by his sprue organism at one time, while at another time it failed to produce gas in these sugars.

In studying the organisms isolated a large number of different mediums were used and the cultural, physiologic, and biochemical properties of these yeasts were studied under a wide range of conditions. The object has been to secure differential methods which are based on procedure ordinarily employed in bacteriologic or mycologic laboratories. At the same time it is realized that additional information along biochemical lines aids in a surer differentiation and gives more insight into the complicated life processes of the organisms concerned. The mediums which have been found most useful are discussed in detail in the next section.

Agglutination and precipitation tests were not attempted. There-is a possibility that some satisfactory basis for specific differentiation may be obtained by the use of these properties, though the results obtained by various investigators thus far have been disappointing.

* Raulin's solution:

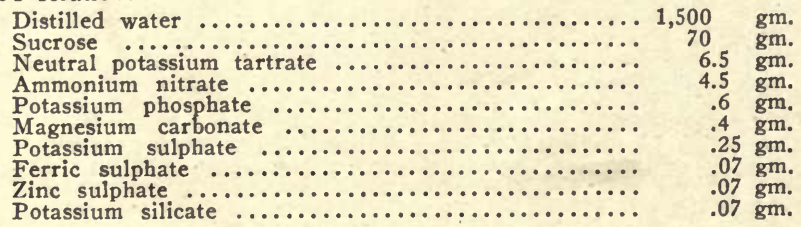




\section{Mediums Employed for Specific D Differentiation}

Sugar Medium.-Hansen has separated the genus Saccharomyces into 6 subgroups based on their fermentative action toward 4 sugars: glucose, sucrose, maltose, and lactose. Guilliermond ('12) has also based his preliminary separation of the genus on these reactions. Castellani ('16) has used a much larger number of sugars and other carbohydrates in differentiating his 'Monilia' species and he emphasizes the importance of acid-formation in the mediums. $\mathrm{He}$ goes to the extreme in this direction in that he separates species in the genus on the basis of slight differences in reaction with sugars alone. Ashford ('15d)., criticizes Castellani and doubts the value of the use of sugar mediums alone. He recognizes the value of such mediums, however, but insists that the results are to be used only in connection with other differentiating characters. Castellani's results should be confirmed by other investigators or a more detailed account of the methods employed by him should be given before his conclusions are accepted. Geiger ('10) has shown that in various sugar mediums, during 3 months, with different yeasts, there may be a decrease, then an increase in acidity, or an increase followed by a decrease, or a steady increase or decrease. Recording the length of time the cultures are grown and the temperature at which they are inoculated is of great importance.

The sugars selected in the present study after preliminary experiments were glucose, sucrose, lactose, maltose, galactose, levulose, and raffinose. Dextrin was used for studies in acid-production and other cultural characters. None of the yeasts investigated produced gas with either lactose or raffinose, but the former was included because it has been generally used by other investigators and the latter because it is a trisaccharid. The importance of using very pure sugars cannot be overemphasized, and the lack of this precaution undoubtedly accounts for the many positive results reported by some investigators for sugars that are not ordinarily fermented.

Fermentation tubes of the Smith type were used in all cases to determine the presence or absence of gas production. The Durham tube-within-a-tube method was tried but proved unsatisfactory. In the determination of acidity a 200 c.c. flask with 100 c.c. of medium was used. The cotton plugs in the flasks were covered with waxed paper held by a rubber band in order to prevent excessive evaporation. The large amount of medium was necessary to allow for the 3 or 4 series of titrations made. The formation of rings, films, and other cultural characters could also be better studied in flasks.

The basic substance employed in the sugar medium may have an important bearing on the nature of the reaction obtained. Since yeast water forms an ideal medium for. the growth of all yeasts studied, and since it has been commonly employed by Will and others working on this group of asporogenic yeasts, it was thought best to employ it as the main basic solution. The results obtained from the use of this medium were not different in most respects from those obtained by the use of 'nutrient broth' as the basic substance, except in the acidity tests. It is important that some standard solution be selected for the use of all investigators, such as is employed by all bacteriologists. The bacteriologic mediums are not entirely satisfactory and are more complex than is necessary for the cultivation of the yeast-like organisms. Since the yeast water solution is easily made and the material used in its composition is generally available, it is recommended that it be made the standard for future investigations on this group.

The yeasts used for inoculation were taken from young cultures on glucose agar slants. The tubes and flasks were run in duplicate with a control set 
uninoculated. Another set of yeast water alone was inoculated with the same organisms. One series was kept at 35-36.C. and another at 25-27 C. Before recording the results with any yeasts several trials were made in order to eliminate chance variation.

The variations in fermentation of sugars recorded by Ashford in the case of his sprue organism were not met with when vigorous young cultures were used. On several occasions when cultures of different ages were taken at random variation was noted. The cause of this variation was not determined, but there is no doubt but that it does occur and should be guarded against.

Litmus Milk.-This medium is useful for separating the yeasts into 3 distinct groups: (1) those which render the milk more alkaline, (2) those which produce no marked change, and (3) those which produce acidity. No yeast studied coagulated milk within 2 weeks, and very few produced acidity. Practically all the forms isolated from feces belonged to the first 2 groups. By acidifying the litmus until it has a strong violet color the change to the alkaline condition is very marked. The tubes were incubated at $25-27 \mathrm{C}$. and 35-36 C. and were observed at frequent intervals.

Gelatin Mediums.-Gelatin-stab cultures are especially useful in determining whether or not the yeast studied produces elongated cells. Yeast water, beerwort, and nutrient broth gelatins were most commonly employed. The beerwort gelatin is most satisfactory for growing giant colonies since it is easily prepared. The stab cultures are most satisfactorily observed in yeast-water gelatin since gas-forming yeast produce bubbles in beerwort gelatin and break up the mediums. The type of growth in gelatin depends to a certain extent on the consistency of the medium and care should be taken to secure a firm gelatin.

A few of the yeasts studied liquefied gelatin while the great majority did not. There was a decided variation in several species which were at one time liquefying, at another not. Such variations may account for the difference in the description given of Oidium albicans by several authors. Frequently old cultures were found to begin liquefaction after they were left several weeks undisturbed. Such liquefaction is probably not due to the activity of the living cells, and should not be regarded as what is ordinarily spoken of as liquefaction.

Three general types of growth in gelatin are observed among the white, nonliquefying group. In the 1 st type there is a more or less uniform, straight, white line following the needle puncture. This is filiform at first but may later become decidedly nodose. Practically all yeasts take this form during the first few days, and then pass over into 1 of the 2 types to be described. The 2nd type has a villous form of growth. Within this type there is a wide variation from forms with individual filaments extending outward at right angles from the axis, like the bristles on a brush, to those having branched bushy filaments. The villous condition may develop early, as in certain Mycoderma types, or it may not appear until the culture is a week old. The denseness of the radiating hyphae, their length, and degree of branching is usually characteristic. Under the hand lens these radiating threads often appear moniliform due to the groups of buds at the ends of the cells of the hyphae. The 3 rd type is really a modification of the $2 n d$, but on account of its importance in distinguishing forms of the Oidium albicans type, it is described separately. At first the growth is filiform; later it becomes somewhat nodose. In about 5 or 6 days after inoculation there appear radiating hyphal elements near the surface of the medium. These may extend to a depth of one-half inch below the surface or may not appear at all. Later from scattered points along the nodose line, fine, individual, bushy growths appear. There may be only 4 or 
5 of these along the entire puncture or they may be so close together that the culture approaches the 2nd type of growth. Occasionally some cultures do not develop these at all. For this reason several cultures were usually made at one time. In other cases instead of the bushy growth appearing, there were developed a number of root-like radiations resembling the secondary roots arising from the tap root. To this group belong Oidium albicans, the sprue organism, and 1 or 2 others which will be described. Plaut ('03b) figures a typical growth of this kind. In the study of the white and golden types described, 52 cultures were tested in gelatin stabs. Of these 30 showed a villous growth, while 22 were nodose or echinulate. In a study of 22 named cultural yeasts, 11 produced a villous growth while the same number did not.

Sugar-Free Mediums.-Aside from milk, the sugar-free mediums were used as checks for the same type of mediums containing sugar. Pellicles, rings, and grease films are produced in these mediums much as in the sugar-containing ones.

Pellicles, Rings, and Grease Films.-A few characteristic cultural developments in liquid mediums need consideration at this point. A gray, dry pellicle containing air is formed within 2 days in the case of the Mycoderma species. This pellicle is characteristic and is easily distinguished from the type to be described next. It resembles the pellicle produced by Bacillus subtilis in bouillon culture. With some yeasts a gradual accumulation of cells on the surface forms a thick, white layer which is moist and easily dislodged. This is usually developed only after several days of growth, and if the tubes are disturbed at intervals it does not appear. In the case of Oidium albicans and the sprue organism this type of growth is present and very characteristic.

With certain species a growth of cells takes place at the surface of the medium where it is in contact with the glass. This soon results in a distinct white ring which frequently becomes dislodged when the tube or flask is disturbed and sinks to the bottom where it still retains its original form. This ring is most distinctive at the end of 2 or 3 days, since species which do not form a distinct ring often give this appearance in older cultures due to the accumulation of cells as the liquid evaporates.

By a grease film is meant a 'scum' which is thin and transparent. It resembles a fine covering of oil in the surface and may be seen at the end of a day or 2 only by holding the flask or tube in such a way as to allow the light to reflect from the surface. Tilting the flask serves to render this more distinct since the film remains attached to the glass and shows a distinct grayish layer above the medium. In dextrin yeast water this scum approaches a pellicle in consistency and can be clearly seen at the end of 3 or 4 days.

Turbidity and sedimentation are not distinctive characters in the yeast cultures, although some yeasts form a clear solution after a week of growth as contrasted with the rather turbid condition in other cultures.

Solid Mediums.-Streak cultures on agar, carrots, and gelatin are useful mainly in distinguishing yeasts of different colors or shades of color, and such gross types of growth are those mentioned earlier. They are of limited value, however, for the differentiation of species on account of the sudden and inexplicable variations which they undergo. All the pink yeasts studied retained characteristic growths on agar and carrot slants under all conditions.

Giant Colonies.-The employment of giant colonies for specific differentiation has been emphasized by Lindner ('05), Will, Geiger, and others. The chief advantage of giant colonies lies in the ease with which they may be photographed and thus serve as comparative charts. The method of developing 
the giant colonies is simple. A 200 c.c. Erlenmeyer flask is filled to a depth of $1.5 \mathrm{~cm}$. with a $12 \%$ beerwort gelatin. A drop from a fresh beerwort culture of the organism is placed in the center of the gelatin. The colony is allowed to develop for 3 weeks or longer and is then photographed. Geiger ('10) recommends the employment of potato and sauerkraut gelatin in addition to the beerwort gelatin. The types of giant colonies produced are fairly constant according to the authors mentioned. In the present investigation a slightly different method was employed. In addition to beerwort gelatin, glucose agar (2\% agar with $2 \%$ glucose, and an acidity of +1 ) was used and Petri dishes of a uniform depth and diameter were substituted for the flasks. Exactly the same amount of medium was placed in each dish, and cultural conditions were kept uniform.

\section{Special Study of 20 Representative Yeasts}

The large number of cultures obtained rendered an intensive study of the entire number impracticable. Moreover, the primary object of the investigation was to work out a scheme by which these yeast-like organisms could be classified in future investigations rather than to make a detailed study of all organisms isolated from the intestinal tract. In order to test the usefulness of the plan proposed, a more intensive study of 20 cultures was made. These were all of the 'white' type except Saccharomyces hominis which gives a slimy yellowish growth on agar slants. Most of these were also of the white glistening type since it was desired to undertake the separation of species which resembled each other closely in gross characters. Several named species were also included in this study to serve as 'controls'. An outline of the procedure used is given. Tables $3,4,5$, and 6 are not arranged in the order of this outline, but are given in the form which was found most convenient in summarizing the results of all the experiments.

1. Morphology

\section{OUTLINE OF PROCEDURE}

1. In young cultures of solid and liquid mediums

2. In old cultures of solid and liquid mediums

3. In hanging drop cultures

4. Ascospore formation

2. Cultural Characters

1. Gelatin-stab cultures

2. On agar and carrot slants

3. In liquid mediums aside from milk

(a) pellicle, ring, and grease-film formation

4. Giant colonies on beerwort.gelatin and glucose agar

3. Physiology (biochemical properties)

1. Carbohydrate reactions, fermentation and acid reactions

2. Litmus milk reactions

3. Gelatin (included in cultural studies)

In Table 3 there is given a summary of the chief cultural and physiologic characters of the organisms together with the sources of the cultures. The numbers and letters to the left are used in subsequent tables and need some explanation. Culture 2.5 was isolated from a patient diagnosed as sprue and has been treated in some detail earlier in this article. The culture was sent to Dr. Ashford* who stated that it was the same as his sprue organism. Culture D is a typical sprue organism received from Dr. Ashford, and is included for comparison. The next 14 cultures were isolated from normal persons with the exception of 158, which was from the case discussed previously in which repeated isolations were made from a woman of advanced age who

- Letter dated Oct. 18, 1916. 


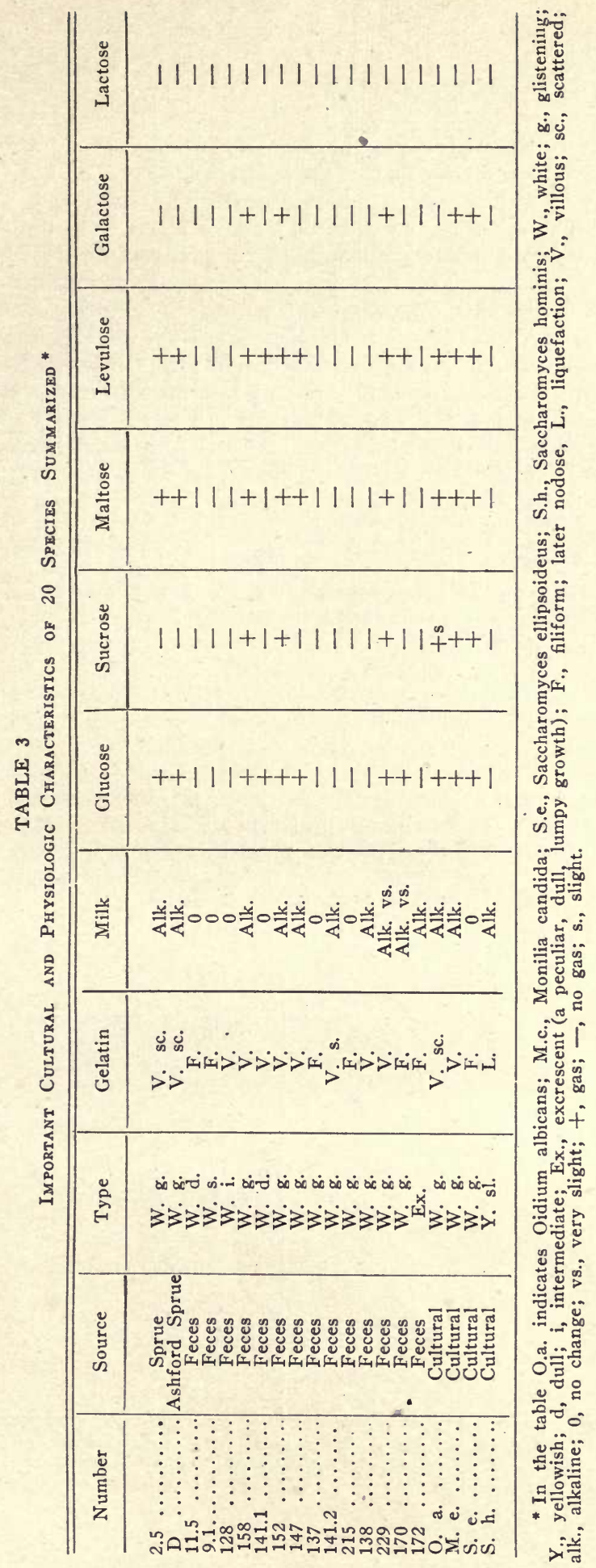


died during the course of the experiment. Oidium albicans culture was secured from St. Thomas' Hospital, London, through the kindness of Dr. H. D. Singer of Kankakee. It was isolated from the mouth of a child who was suffering from thrush. The other named cultures were obtained from the "Centralstelle, für Pilzkulturen," Amsterdam, Holland. Saccharomyces hominis Busse is supposed to be a subculture of Busse's ('95) original organism. Guilliermond states, however, that this organism is supposed to ferment glucose and not liquefy gelatin, neither of which reactions agrees with the results given in Table 3. Saccharomyces ellipsoideus is probably a composite species. The data under the head of 'type' give merely the type of growth of young agar slants. Under 'gelatin' is included a rough division into the 3 types outlined earlier. The reactions with sugars are based, in each case, on a number of trials. On the basis of the fermentation of sugars alone, the 20 species may be separated into the following groups:

Group 1. Those not fermenting sugars ....

Group 2. Those fermenting all except lactose

Group 3 Those fermenting glucose, maltose and levulose but not sucrose, galactose, or lactose ..........

Group 4. Those fermenting glucose and

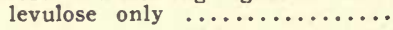

Group 5. Those fermenting glucose, sucrose, maltose and levulose, but not galactose or lactose ............
$11.5,9.1,128,215,172,138,137$, S. hominis, 141.2

158, 152, 229 M. candida S. ellipsoideus

2.5 , D. O. albicans, 147

$141.1,170$

It has been found, as mentioned, that there is some variation in the reactions toward sugars. This is especially true of the members of the 3 rd group; sucrose and galactose are fermented at times by these organisms, and at other times not.

TABLE 4

Change in Acid Reaction Brought About by 20 Cultures Incubated at 35 C. for 6 Days

\begin{tabular}{|c|c|c|c|}
\hline Number & Raffinose & Lactose & Glucose \\
\hline 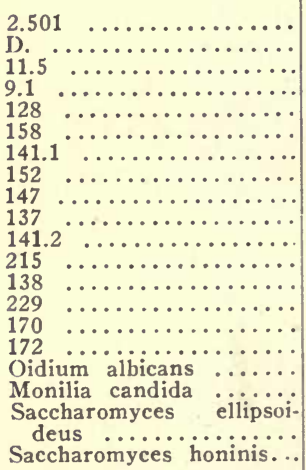 & $\begin{array}{r}-2.5^{*} \\
-5.0 \\
-1.0 \\
0.0 \\
-5.0 \\
-5.0 \\
-2.5 \\
-5.5 \\
-3.0 \\
-2.5 \\
? \\
1.0 \\
-4.5 \\
0.0 \\
0.0 \\
0.0 \\
-5.5 \\
-4.5 \\
0.0 \\
1.0\end{array}$ & $\begin{array}{r}-2.5^{*} \\
-5.0 \\
-1.0 \\
1.0 \\
-6.0 \\
-6.5 \\
-3.5 \\
-4.5 \\
-2.5 \\
0.0 \\
-0.5 \\
0.5 \\
0.0 \\
-5.5 \\
0.0 \\
0.0 \\
-4.5 \\
-5.5 \\
1.0 \\
1.0\end{array}$ & $\begin{aligned} & 0.0^{*} \\
&-4.5 \\
& 2.0 \\
& 1.0 \\
&-0.5 \\
&-3.0 \\
&-4.0 \\
&-5.5 \\
&-2.0 \\
& 1.0 \\
& 1.0 \\
& 0.0 \\
&-2.5 \\
&-4.0 \\
& 2.0 \\
&-2.0 \\
&-5.0 \\
&-6.0 \\
& \\
& 3.0 \\
& 3.0\end{aligned}$ \\
\hline
\end{tabular}

* The results are given in terms of the number of cubic centimeters of $\mathrm{n} / 10 \mathrm{NaOH}$ required to neutralize 100 c.c. of the culture solution, assuming the original reaction to be exactly neutral. If there was a loss of acidity it is expressed by the negative sign. 


\section{Production of Acidity añd Alkalinity in Liquid Mediums}

Table 4 gives the results of the titrations of cultures in several carbohydrate mediums. These results represent the total acidity or alkalinity at the end of the period indicated in the table. The tests, as here recorded, are intended mainly to indicate whether the organism concerned renders the medium decidedly alkaline or acid after a period of growth.

It is unfortunate that those who have used the reactions with carbohydrate mediums for specific separation in the yeasts have not used more care in recording their results. Usually the descriptions of the methods employed are entirely lacking and the results are recorded in a table as positive or negative, without indicating the length of time after inoculation when the tests were made or the total amount of acid produced. The basic substance employed in making the carbohydrate mediums and the initial acidity are not given in most cases.

Will and Geiger have been more careful in this respect and their results show that the time at which the titrations are made is very important. It is strange that Castellani should find acid developed in most of his carbohydrate mediums with a large number of his Monilia species while a decided alkaline reaction in milk is recorded for these same species.

In order to make a more careful study of the changes in acidity during the first month of growth in liquid mediums, 6 of the 20 organisms selected were grown in flasks of yeast water alone and also with the carbohydrates added. These were tested at 3 periods, as indicated in Table 5.

The original acidity of the yeast water was near +1 to phenolphthalein. Uninoculated flasks were always incubated with the others and titrated at the ends of the periods as in the case of the inoculated ones. This precaution was used in order to show that the little evaporation which occurred did not have a decided effect on the results, and to give a large number of check titrations of the original mediums. The titrations were made against $n / 20$ $\mathrm{NaOH}$ using phenolphthalein as an indicator. The results are expressed in the number of cubic centimeters of $n / 10 \mathrm{NaOH}$ it would require to neutralize the acid produced in 100 c.c. of the medium. If the acidity decreased instead of increased it is expressed by a negative sign; in other words, it would take this amount of $\mathrm{n} / 10 \mathrm{HCl}$ to neutralize the alkali in 100 c.c. of the medium. Five c.c. portions were withdrawn by means of sterile pipettes, and the average of 2 titrations was taken in all cases except at the end of the final period, when 3 titrations were made from each flask.

Discussion of Results.-The results given in Tables 4, 5, and 6 are evidence that the reactions brought about by the intestinal yeasts are variable, not only among different species but in the same species with different carbohydrates. It is also evident that titrations made at different times during the course of the growth show variations in the same species. The temperature at which the cultures are kept also has an influence on the degree of acidity. That the change in acidity is not due primarily to the carbohydrate present is evidenced by the fact that yeast water without the addition of carbohydrates gave similar results to the yeast water carbohydrate mediums. The addition of certain carbohydrates tend, however, to vary the degree 
TABLE 5

Reaction of Yeasts on Sugar Mediums

At 35 C.

\begin{tabular}{|c|c|c|c|c|c|c|c|}
\hline \multirow{2}{*}{$\begin{array}{l}\text { Name or } \\
\text { Number }\end{array}$} & \multicolumn{3}{|c|}{ Yeast Water } & \multicolumn{3}{|c|}{ Glucose } & \multirow{2}{*}{$\frac{\text { Lactose }}{5 \text { Days }}$} \\
\hline & 5 Days & 2 Weeks & 5 Weeks & 5 Days & 2 Weeks & 5 Weeks & \\
\hline $\begin{array}{c}2.5 \\
215.13 \\
170.1 \\
158.3 \\
152.1 \\
\begin{array}{c}\text { Oidium } \\
\text { cans }\end{array}\end{array}$ & $\begin{array}{l}-6.0^{*} \\
=2.5 \\
-2.0 \\
-6.5 \\
-4.5 \\
-8.5\end{array}$ & $\begin{array}{l}-5.5 \\
-2 \\
-4 \\
-6 \\
-7 \\
-6.5\end{array}$ & $\begin{array}{l}-5.5 \\
=4 \\
=4 \\
=4 \\
=-5.5 \\
-7.5\end{array}$ & $\begin{aligned} & 0 \\
& 2 \\
& 2 \\
&- 3.5 \\
&--3 \\
&- 3\end{aligned}$ & $\begin{array}{r}-5 \\
4.5 \\
0.5 \\
-5.5 \\
-5.5 \\
-5\end{array}$ & $\begin{array}{c}-8 \\
7 \\
1 \\
-5.5 \\
-7 \\
6\end{array}$ & $\begin{array}{l}-7 \\
=0.5 \\
-2.5 \\
-7 \\
=7 \\
-7.5\end{array}$ \\
\hline Check & 0 & 0 & 0 & 0 & 0 & 0 & 0 \\
\hline
\end{tabular}

At 25 C.

\begin{tabular}{|c|c|c|c|c|c|c|c|}
\hline $\begin{array}{c}2.5 \\
215.13 \\
170.1 \\
158.3 \\
152.1 \\
\begin{array}{c}\text { Oidium albi- } \\
\text { cans } \\
\text { Check }\end{array}\end{array}$ & $\begin{array}{l}-7.5^{*} \\
-3.5 \\
0 \\
-7 \\
-6 \\
-7 \\
0\end{array}$ & $\begin{array}{l}-10 \\
-5.5 \\
-4 \\
-5.5 \\
-8 \\
-10 \\
0\end{array}$ & $\begin{array}{c}-7 \\
-7 \\
-6 \\
-5.5 \\
=7.5 \\
-7 \\
0\end{array}$ & $\begin{array}{c}-7 \\
1 \\
2 \\
-2.5 \\
-3 \\
-6.5 \\
0\end{array}$ & $\begin{array}{c}-7 \\
2 \\
0 \\
-7.5 \\
-5.5 \\
-6.5 \\
0\end{array}$ & $\begin{array}{l}-8 \\
0.5 \\
1 \\
-7.5 \\
-7 \\
-8.5 \\
0\end{array}$ & $\begin{array}{l}-6.5 \\
=4 \\
=5 \\
=7 \\
=7.5 \\
-7 \\
0\end{array}$ \\
\hline
\end{tabular}

- The results are given in terms of the number of cubic centimeters of $n / 10 \mathrm{NaOH}$ required to neutralize 100 c.c. of the culture solution, assuming the original reaction to be exactly neutral. If there was a loss of acidity it is expressed by the negative sign before the number. The check had an initial acidity of +0.95 , but is recorded as 0 in order to compare with the other cultures.

of acidity, as shown, for example, by the extreme alkalinity of dextrin solutions.

In general, when yeast water with an initial acidity of +1 is used with or without carbohydrates there is a decided decrease with some species, while others show no marked change in the final reaction in acidity. In spite of the wide variations in results due to these various conditions, there are certain constant differences between species which are useful in specific characterization. It will be seen from Tables 5 and 6 that Oidium albicans is a species which decreases the acidity of the mediums in every case. It is also evident that the reactions of Culture 2.5 are of the same general character as those of Oidium albicans. On the other hand, Cultures 170 and 215.13 do not bring about a decided decrease in acidity in any of the mediums. These results are constant throughout the entire range of mediums and under both conditions of temperature.

The necessity of stating the period of time the culture has been growing before the test of acidity is made is emphasized by the results obtained after 5 days with Culture 2.5 and Oidium albicans. 
TABLE 5-Continued

Reaction of Yeasts on Sugar Mediums

At 35 C.

\begin{tabular}{|c|c|c|c|c|c|c|c|}
\hline \multicolumn{2}{|c|}{ Lactose } & \multicolumn{3}{|c|}{ Sucrose } & \multicolumn{3}{|c|}{ Dextrin } \\
\hline 2 Wecks & 5 Weeks & 5 Days & 2 Weeks & 5 Weeks & 5 Days & 2 Weeks & 5 Weeks \\
\hline $\begin{array}{l}-6 \\
-6.5 \\
0.5 \\
-5 \\
=5 \\
-4.5\end{array}$ & $\begin{array}{c}-5 \\
1 \\
0.5 \\
-4.5 \\
-4 \\
-3.5\end{array}$ & $\begin{array}{l}-2.5 \\
z^{-1.5} \\
z^{-4.5} \\
=6 \\
-0.5\end{array}$ & $\begin{array}{l}-3.5 \\
1.5 \\
-3.5 \\
=4.5 \\
-6 \\
-3.0\end{array}$ & $\begin{array}{l}-6 \\
-1.5 \\
1.5 \\
-4.5 \\
-6.5 \\
-7\end{array}$ & $\begin{array}{l}-7 \\
=3.5 \\
=4.5 \\
=11.5 \\
=10 \\
=11\end{array}$ & $\begin{array}{l}-7.5 \\
=2.5 \\
=4 \\
=9 \\
=9 \\
-8.5\end{array}$ & $\begin{array}{l}-7.5 \\
=1.5 \\
=1.5 \\
=10 \\
=10 \\
=8.5\end{array}$ \\
\hline 0 & 0 & 0 & 0 & 0 & 0 & 0 & 0 \\
\hline
\end{tabular}

At 25 C.

\begin{tabular}{|c|c|c|c|c|c|c|c|}
\hline $\begin{array}{l}-6.5 \\
=4 \\
=5 \\
=5.5 \\
=6.5 \\
-9.5\end{array}$ & $\begin{array}{l}-6.5 \\
=2 \\
-3 \\
=5.5 \\
=6 \\
-7\end{array}$ & $\begin{array}{l}-8 \\
Z^{3} \\
Z^{5} \\
=5.5 \\
=6.5 \\
-7.5\end{array}$ & $\begin{array}{l}-6 \\
1 \\
-6 \\
-6.5 \\
-6.5 \\
-5.5\end{array}$ & $\begin{array}{l}-6.5 \\
\text { 二-5.5 } \\
\text { - } \\
\text { - } 9.5 \\
-9.5 \\
-4.5\end{array}$ & $\begin{aligned} & 9.5 \\
&= 5 \\
&= \\
&= 11.5 \\
&= 8.5 \\
&-11.5\end{aligned}$ & $\begin{array}{l}-11.5 \\
=7 \\
=5.5 \\
=10.5 \\
=11 \\
-7\end{array}$ & $\begin{aligned}= & 8.5 \\
= & 7 \\
= & 5 \\
= & 11.5 . \\
= & 9.5\end{aligned}$ \\
\hline 0 & 0 & 0 & -0 & 0 & 0 & 0 & 0 \\
\hline
\end{tabular}

In sucrose and glucose at $35^{\circ} \mathrm{C}$. the reactions of these are not different from those of Cultures 170 and 215.13. If the cultures are allowed to grow a month, however, the results are different.

Dextrin yeast water appears to be an unusually good medium for differentiating between those species which decrease acidity and those which produce little change. The differences are very sharp and take place within a short time, especially when the cultures are kept at $35 \mathrm{C}$.

On the whole, the exact determination of changes in acidity during a period of growth is believed to be of little value on account of the wide variation within a single species even under apparently the same cultural conditions. Increase or decrease in acidity, as revealed by titrations after a week or more of growth, is of value in differentiating species, in that some species tend to constantly decrease the acidity while others bring about no decided change. The initial acidity of the mediums should be determined and stated since this has an important influence on the final reaction. The substances employed in the preparation of the carbohydrate mediums should be stated in all cases since the carbohydrates themselves are not usually the cause of the change in acidity although they may influence the reaction. 
TABLE 6

Reaction in Litmus Milix of 96 Yeasts, 20 Days *

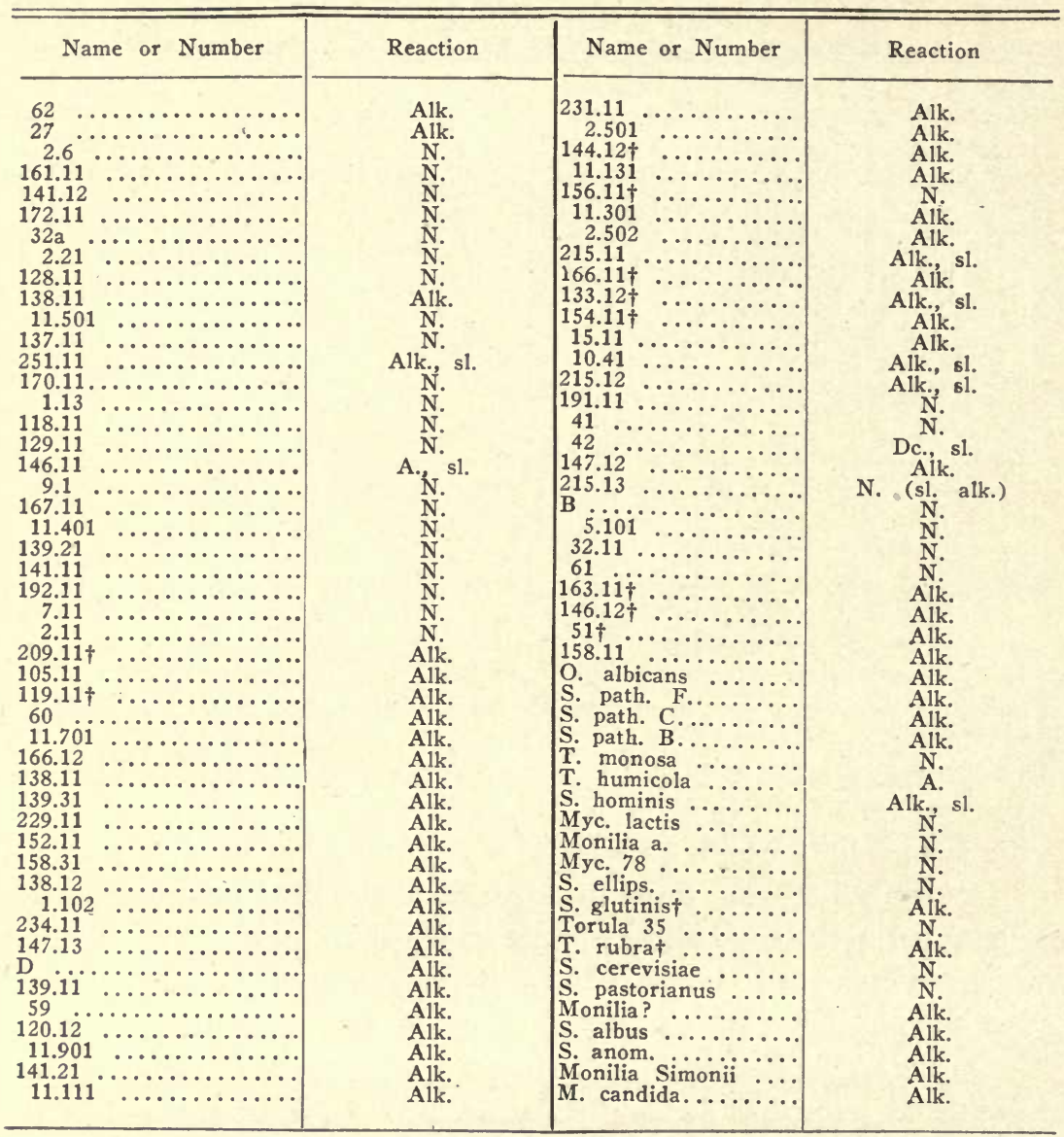

* In the table Alk. indicates alkaline; N., neutral; no change; A., acid; sl., slight degree of change; Dc., decoloration; O., Oidium; S., Saccharomyces; F., Foulerton; C., Curtis; B., Binot; T., Torula; Myc., Mycoderma; Monilia Simonii, usd for convenience only, and does not signify that this species is named from a botanic standpoint.

$\dagger$ Pink yeasts.

\section{Comparison of Yeasts Isolated from the Digestive Tract with Determined Pathogenic and Nonpathogenic Species}

The question naturally arises whether the yeasts isolated from the digestive tract are similar to, or identical with, those associated with diseaser The present investigation did not include extensive studies of pathogenic species, but a number of these were secured and used for comparison, not only with the intestinal yeasts, but also with those secured from other sources. Saccharo- 
myces hominis, Torula humicola, Blastomyces dermatitidis, Oidium albicans, Torula rubra, Monilia X of Ashford, Simon's ('16), Binot's ('03), Curtis ('95), and Foulerton's ('99) pathogenic yeasts were those most carefully studied. The nonpathogenic determined yeasts used are given in Table 2.

The pathogenic yeasts most nearly resembling the intestinal fungi isolated were Oidium albicans,* Monilia X of Ashford, and Simon's species. Ashford's Monilia has many characters in common with Oidium albicans, and considering the wide variation in cultural and biochemical characters which this species apparently undergoes it is questionable whether the fungus associated with sprue is a distinct species. Ashford ('15c) writes that his organism is not Monilia albicans, but does not state the grounds on which he bases his assertion. Culture 2.5, isolated from a case diagnosed as sprue, is the same as Ashford's Monilia X. This was the only culture in the entire number isolated which closely approached Ashford's sprue organism, with the exception of Culture 147.103 which gave the same reactions in sugar mediums but differed in its morphologic characters and type of giant colony formed. In general, however, the type of growth produced by the sprue organism resembles a large number of the yeasts studied in that it forms a white, glistening, firm surface which remains moist, heaped, and chalk-white.

The pathogenic yeast of Simon also has many characters in common with the sprue and thrush organisms. It forms the same type of surface growth and produces similar reactions in sugar mediums, as well as the peculiar villous growth in gelatin-stab culture. It was received too late in this investigation to make a complete study of all its biochefnical characters.

Blastomyces dermatitidis is decidedly different in most of its characters from any of the yeasts isolated, as well as from the other pathogenic yeasts. The production of a dry, fluffy, aerial mycelium, commonly formed in old cultures of this organism, is a character not possessed by any of the yeast-like organisms under consideration. There is also a marked tendency of this fungus to grow beneath the surface of the agar slant forming a tough, leathery, mycelial layer from which arise tufts of hyphae, strongly resembling Indian wigwams. The budding condition is not predominant in this fungus and, as stated later, it is not to be considered as a yeast.

The remaining pathogenic yeasts mentioned above differ from those isolated from the intestinal tract in their cultural characters especially. While the majority of the intestinal species form a distinctly chalk-white growth on agar slants which becomes only slightly darker with age, Saccharomyces hominis, Torula humicola, and the pathogenic yeasts of Curtis, Foulerton, and Binot develop more or less slimy growths which become brown, yellowish-brown, or ash-gray in color. There are also marked morphologic distinctions between these species and those of the intestinal tract.

A comparison of the nonpathogenic yeasts listed in Table 2 with those from the intestinal tract demonstrates that these 2 groups have many characters in common. The chalk-white streak on agar slants is commonly developed by a number of species in both groups, while the spreading Mycoderma type of growth occurs in a number of the intestinal species, as well as in the true

* The specimen of Oidium albicans used in this study was obtained from the St. Thomas Hospital in London and was stated to be a typical culture from the tongue of a child suffering from an undoubted case of thrush. (Letter from Dr. Frank Babtree, dated March 3 , 1917.) This form does not liquefy gelatin readily, nor đoes it clot milk. Castellani ('16) describes 7 'forms' of this species none of which liquefy gelatin, while 6 of them clot milk, He states that the name 'Monilia albicans' should be reserved for the form which clots milk' and liquefies gelatin. He regards these forms as being different species, although he does not name them, and is of the opinion that there is a plurality of species causing thrush. 
Mycoderma species studied. Many of the red yeasts from the intestinal tract were indistinguishable from Saccharomyces glutinis and Torula rubra in gross characters. However, it was not possible to demonstrate that any of the species isolated were identical with Saccharomyces cerevisiae, S. ellipsoideus, and other culture yeasts. Several of the isolated species, for example, 152 and 158.3, were very similar in their biochemical properties to Monilia candida.

A number of wild yeasts were also isolated from the air and from decaying fruits and vegetables. These were even more closely related to the intestinal organisms than were the nonpathogenic yeasts listed in the table. In the light of the feeding experiments described later, it is certain that these yeasts, when ingested with the food, will pass through the alimentary tract in a living condition and may be isolated from the feces. It is probable, therefore, that the majority of the yeasts isolated in this investigation are these wild species so common in nature. That there is no one yeast species common to the intestinal tract of man is demonstrated by the fact that the majority of the numerous cultures isolated showed, from even a superficial study, that they were of distinct species. It is interesting to know, in this connection, that Saccharomycopsis guttulatus is constantly found in the intestinal tract of rabbits. This species was not met with in the course of the present investigation, and is certainly not common in the intestinal tract of man.

\section{FEEDING EXPERIMENTS WITH YEASTS}

The most exhaustive feeding experiments with yeasts were those carried out by Neumayer ('91) referred to in a previous section. In these experiments, however, the investigator used only a few species of yeasts and these were, for the most part, the usual fermenting forms of commerce. Neumayer proved that the various secretions encountered throughout the alimentary tract were either favorable for the development of the yeasts or neutral in their influence. Those secretions which were harmful had little influence on account of the fact that the yeast cells quickly passed beyond their influence, and the short period during which the cells were in contact with them was not sufficient for harmful action. He also observed that the yeasts found in the feces were not in a budding condition and that many of them were dead. He proved that, while the sum of the conditions in the digestive tract was not favorable for development and multiplication of these fungi, they still were able to survive in comparatively large numbers. The result of his experiments shows that the ordinary fermenting yeasts and wild yeasts found in beer and grape must are not harmful when fed alone, but may cause serious illness when fed with fermentable carbohydrates.

Few other investigators have attempted to prove the pathogenicity or yeasts by feeding, seemingly preferring to inject the organism into the blood stream or into the peritoneal cavity. Ashford ('16) has made a complete series of experiments on laboratory animals with his sprue organism. In his feeding experiments he found that the fungus is 
pathogenic only when recently isolated or after it has passed through some susceptible animal. This may explain the negative results of others in their injection experiments.

In order to test and extend the results obtained by Neumayer and Ashford, and especially to gain more insight into the fate of the ingested yeasts, a number of experiments were undertaken with the yeasts previously isolated or with certain commercial yeasts having well defined characters.

The yeasts selected were those having some distinctive character so that they could be quickly recognized when reisolated from the feces. The following species were used:

1. S. glutinis (red)

2. 51 (red and forming a peculiar wrinkled colony)

3. S. anomalus (distinctive ascospores)

4. 11.5 (produces ascospores of a peculiar type and has a distinctive growth)

5. D (a culture of Dr. Ashford's sprue organism)

A number of other species were used but since the results do not differ in any way from those here obtained they are not included. The methods used and the results obtained for the first 4 organisms given were identical and will be discussed together. The yeasts were grown on an agar slant for several days and then a mass about the size of a grain of corn was swallowed. Cultures were always ingested within a few hours after the passage of stools and in most cases the first sample of feces was obtained within 30 hours. Samples also were taken from stools just previous to feeding and plates were made from these in order to exclude the possibility of any species being present in sufficient quantity to interfere with the experiment. Since the person used had been previously tested a number of times for other isolations, it was known that few yeasts were normally present in the feces.

Ten plates were made from 10 different portions of the stools in the case of each sample. Subsequent stools during the course of a week or 10 days were tested in the same manner. After feeding 1 species, a period of several days was always allowed before the next feeding, in this way eliminating the possibility of confusing the 2 species fed. The tests were made on a person in good health and showing a history free from gastro-intestinal troubles in recent years. No effort was made to control the diet which consisted of the normal mixed food of a healthy person with a large amount of carbohydrates.

The first stools following the feeding always contained large numbers of the particular yeast ingested. All the plates gave numerous colonies and most of them usually showed over $50 \%$ positive results, while many developed colonies of the yeast ingested at $100 \%$ of the points of contact. The yeasts seemed to be fairly evenly distributed throughout the stools, although microscopic examination showed them more abundant in some mounts than others. Under the microscope the majority of the cells were seen to be of a faint yellow color and few of them were budding. They did not appear to be in an active growing condition, but most of them seemed to be living. A careful examination of the plates was always made to discover, if possible, foreign types of yeasts. In several cases when pink yeasts were fed, 3 or 4 white colonies in the entire 10 plates appeared, and the reverse was true when white yeasts were ingested. 
This result was to be expected in the light of the previous experiments on this person.

In 2 of the first 4 experiments the plates taken from the 2 nd stools, that is, about 24 hours later, showed a few scattered colonies of the same species that was ingested. In subsequent stools no trace of the original yeast could be found.

The fact that the yeasts were found distributed fairly evenly throughout the stools is to be explained only on the ground that the ingestion of the organisms so soon after the passage of the previous stools permitted a mixture of the cells with the food in the stomach. It is probable that the yeasts are able to multiply in the stomach, due to the favorable acid condition and the lack of harmful secretions. They are then passed on with the food and from this point probably do not find conditions conducive to rapid multiplication. The absence of these yeasts in subsequent stools indicates that they pass along with the food, and that the few which do remain in the stomach or intestine are not able to multiply to any great extent hefore they are finally passed out in subsequent stools. The fact that they are not able to establish a foothold anywhere along the way is of fundamental importance, since the rich carbohydrate food which passes through the digestive tract would give them an opportunity to produce harmful products within the body.

The person to whom these various species were fed suffered no inconvenience during the course of the experiments. When yeasts with power of active fermentation were fed, as for example, Saccharomyces ellipsoideus, there sometimes resulted a slight 'full' feeling a few hours later, but this was not of long duration, and apparently no large amount of gas was developed either in the stomach or the intestine.

A more detailed account of the feeding experiment with the sprue organism from Dr. Ashford is necessary. This culture was pronounced a typical sprue organism by Dr. Ashford and agreed fully with his description of the typical sprue yeast. On the basis of his results with animals, he expresses the opinion that the virulence of the yeast is lost after being on mediums for some time, and this virulence can be regained only by passing the culture through some susceptible animal. Since my culture had been on mediums for some months and had presumably, to a large degree lost its virulence, it was decided to test its period of life in the digestive tract of the person previously fed with the other culture yeasts. Therefore, a mass of about $1 \mathrm{gm}$. was taken from the surface of an agar slant and ingested without other food. This feeding took place a few minutes after the passage of stools which were saved and tested, with negative results. No pain was felt during the first day after feeding and no intestinal disturbance was noticed. Unfortunately, there was no passage of stools for over 48 hours, and some of the symptoms subsequently described may have been due to the constipated condition of the person. The first stools secured were very hard and lumpy. The results of plating were the same as in other feeding experiments, except that the first inch of the feces gave entirely negative results.

After the first 48 hours considerable discomfort to the person resulted. An 'uneasy' feeling in the intestine, with pain in the region of the stomach, and 'heartburn' were noticed. However, at no time was there excessive gas in the stomach or intestine, and no tendency toward a diarrheal condition. The next passage of stools was also delayed, occurring 36 hours after the first. This was plated and gave a large percentage of the type ingested. There were several colonies of pink yeasts in the plates from the 1 st stools but none in those of the 2nd. Peniciliium colonies in considerable numbers appeared in these plates. All parts of the 2nd sample gave the sprue organism and the 
colonies were evenly distributed. The 3rd passage, 24 hours later, was of normal consistency, although the pains in the region of the intestine were still acute. Samples from this stool were plated but the agar was unsatisfactory and no accurate results were obtained. Sufficient colonies appeared, however, on 1 good plate to indicate that the organisms were still present. The 4 th stool gave a large percentage of the sprue organism. The number of positive contacts was somewhat reduced in these plates, but several of them yielded over $50 \%$. This 4 th sample was taken 6 days after the ingestion of the yeasts and is the only case in which more than 2 successive stools gave colonies of the organism ingested. The next 2 stools were not saved on account of the pressure of other work, but the pain in the stomach and intestine disappeared and subsequent stools gave entirely negative results. The rather sudden disappearance of the yeasts was unexpected and difficult to account for.

During the course of this experiment the person fed on his normal diet. Carbohydrates did not constitute as large a percentage of the food as normally, but were not much less than the average person would use.

The most important conclusion to be drawn from this experiment is that this yeast differs from all others investigated in that it was able to remain and seemingly to develop in the alimentary tract. It is not conceivable that the small number of yeasts fed could continue to give positive results over this long period unless they did multiply during the time they were in the intestional tract. Unfortunately, no attempt was made to determine whether or not they were present in the stomach after the first 48 hours. While the other yeasts investigated seemed to pass through the alimentary tract as so much waste food, except for a possible brief period of multiplication in the stomach, this organism undoubtedly was able to carry on its normal processes and secure at least a temporary foothold somewhere in the digestive canal. The mere presence of active yeasts in the intestinal tract for a long period of time would, undoubtedly, give rise to harmful by-products, as maintained by Neumayer. If, in addition to this, they are able to establish themselves in the mucous membrane, as do the thrush and sprue organism, their presence would lead to serious results.

\section{THE CLASSIFICATION OF B BUDDING FUNGI}

The fungi having budding stages in their life cycles are of 3 types: (1) those in which budding is a secondary phase, usually occurring under unusual or abnormal conditions, or during only a short period of the life cycle of the organism; the primary phase consists of a distinct mycelial development; (2) those in which budding is the primary phase, occurring under all the usual conditions of growth, but always with mycelial formation, more or less rudimentary, as a secondary phase; (3) those in which budding is the only known method of vegetative multiplication. 
The first group includes a number of species from diverse orders of fungi. The smuts (Ustilaginales) commonly produce large numbers of cells from the primary sporidia by the budding process. The basidiospores of species of Calocera, Tremella, and many other basidiomycetes, and the ascospores of certain ascomycetes, such as Sphaerulina intermixa, and various species of Taphrina, produce new cells by budding. Hesler ('16) describes the production of 'microconidia' by budding of the hyphae in Physalospora Cydoniae, and Alwood ('98) records the occurrence of a yeast-like form in cultures of this same species, but does not account for its origin. Mucor racemosa when placed in sugar solutions forms budding cells similar to yeasts in a budding condition. Dematium pullulans produces an extensive mycelium from the filaments of which there are numerous buds. In some fungi the budding stage is more prominent than in those cited; for example, the organism described by Gilchrist and Stokes ('95), Ricketts ('01), and others as causing a serious skin disease, and commonly called Blastomyces dermatitidis, has an extensive budding phase in its life cycle. Under certain, little understood conditions it continues budding for a long period. Sooner or later, however, it forms a white, fluffy, aerial growth which sharply distinguishes it from the yeast-like fungi.

To the 2nd group belong those forms which are predominantly budding. They form a firm, moist growth on solid mediums and rarely produce aerial mycelium. Under certain conditions they form elongated cells which become septate but rarely branch. Monilia candida and species of Endomyces are examples of this group.

The last group, which includes the strictly budding species, embraces the greater part of the Saccharomycetaceae, or the spore forming yeasts, and those commonly placed in the genus Torula by writers following Hansen's definition of this genus. This and the second group are subdivided on the basis of whether or not ascospores are known to occur in their life cycles.

\section{TAXONOMIC DISCÚSSION}

The position of the asporogenic yeast-like organisms among Fungi has not been satisfactorily determined. As will be shown, they have been placed in a number of diverse genera under the different schemes of classification.

The systems of classification of the fungi most generally followed by mycologists and botanists are those presented by Lindau, in Engler and Prantl's "Die Natürlichen Pflanzenfamilien," and by Saccardo in his "Sylloge Fungorum." Since the classification of Fungi imperfecti is practically the same in the 2, this system will be spoken of as Saccardo's classification. In this system there are 4 classes of fungi: Phycomycetes, Ascomycetes, Basidiomycetes and Fungi imperfecti, the last class being a provisional one for the inclusion of all the fungi not having a perfect or sexual stage, or this stage not having been discovered as yet. The endospore forming yeasts are placed in the Ascomycetes under the family Saccharomycetaceae, while those not forming spores should logically be placed in the Fungi imperfecti. The Fungi imperfecti are divided into 3 orders, Sphaeropsidales (Phoma- 
tales), Melanconiales, and Moniliales (Hyphomyceteae). The 3rd order includes 4 families, Moniliaceae (Mucedineae), Dematiaceae, Stilbaceae, and Tuberculariaceae. We are concerned with the first of these families only since the yeast-like fungi under discussion would be included in this group on account of their color and simple organization.

Frank ('86) has separated the fungi into the following orders: Ascomycetes, Basidiomycetes, Zygomycetes, Phycomycetes, and Blastomycetes. He also has a provisional group of the Fungi imperfecti, but includes all the budding fungi, whether spore forming or not, in the order Blastomycetes.

Vuillemin ('10) has suggested another classification for the mycoses of animals. He has 2 orders, Hyphales and Siphales, the latter including all phycomycetes of the Saccardian classification. The Hyphales are divided into Microsiphones, Conidiospores and Thallospores. Conidiospores are those fungi which form their conidia as distinct fructifications on more or less specialized branches of the mycelium (thallus), while Thallospores are those which form their reproductive bodies directly from the thallus or mycelium. The latter group he divides into Arthromycetes and Blastomycetes, according to whether the spores are produced as a part of the body of the thallus or by budding of the cells. The fungi under discussion, therefore, would be placed in Blastomycetes. It is from the use of these various systems by different writers that so much confusion has arisen in the classification of the yeast-like organisms.

The last 2 classifications mentioned place considerable emphasis on the building process, although in Frank's system this is not the only distinguishing character of the group. Vuillemin, working with animal pathogens, naturally regarded this as a very important character.

I believe that the importance of the budding process has not been sufficiently emphasized in the classification of Saccardo. None of the authors mentioned has laid sufficient stress on the essentially unicellular condition in this group.

Since the system of classification of Saccardo is so generally established, it is thought best to adapt it to the forms under discussion. It is believed that the family Moniliaceae should include a subfamily into which those forms which are essentially unicellular and budding can be placed and that the description of the family should be emended to include such subfamily. For the present, however, they will be placed in the tribe Oosporeae, as defined by Lindau. 
The question of the generic position of the asporogenic yeasts is still more confusing and a special discussion of this point will be entered into here.

The yeast-like fungi without endospore formation have been placed by various writers in one or another of the genera listed below. Those genera are excluded which include endospore formation as an essential feature of their classification. Genera such as Saccharomyces and Endomyces have been used to include the asporogenic forms, by a nuniber of authors, on the same grounds that certain rusts are included among Basidiomycetes, although their 'perfect' forms are not known. Each genus in the accompanying list is followed by the name or names of the writers who have used it most prominently to include the typical asporogenic yeasts.

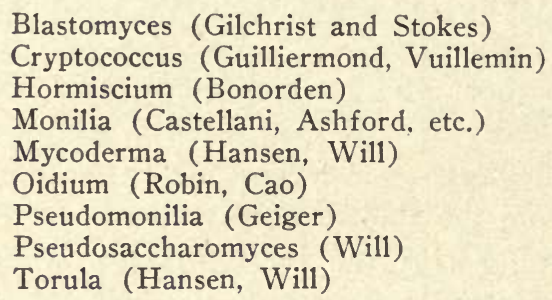

The classification used by de Beurman and Gougerot ('09) includes the genera Zymonema, Atelosaccharomyces and Parasaccharomyces, all $\simeq$ f yeast-like character. These will be discussed further.

Accepting as final the rulings of the Brussels Congress on the naming of the fungi, the writer has not attempted to antedate Fries ('21-'32) in the discussion of these genera, except where earlier descriptions aid in clearing up certain vague points in the description: of later writers.

The genus Torula has been used by practically all investigators, interested especially in fermentative industries, to include all the asporogenic yeasts which do not form a distinct pellicle in liquid mediums, those forming a pellicle being placed in the genus Mycoderma. Hansen, Will, Guilliermond, and Lindner accept this interpretation of the genus. On the other hand, the mycologist regards those dark colored forms which form chains of spores resembling a necklace of beads as true Torula species. Thus Saccardo and Lindau have both placed this genus in the family Dematiaceae which is made up of dark spored forms. The genus Torula was founded by Persoon and emended by Fries, who used as his type species Alternaria tenuis of 
Persoon. This is described by Persoon ('22-'28) as having darkcolored spores, which character justifies later authors in placing this genus in the Dematiaceae. Turpin ('38) studied the budding yeast plants in beer and named them Torula cerevisiae. He had the impression that they were a stage in the life of a plant which, in the presence of abundant oxygen gave first Mycoderma cerevisiae and later Penicillium glaucum. Hansen and others have used Turpin's description as a basis for including all asporogenic yeasts of this character in Torula.

Sumstine ('13) and Vuillemin ('11) discuss at length the genus Monilia from a taxonomic standpoint. The former states that, judging from Persoon's description and synonymy, Monilia is congeneric with Aspergillus and Penicillium. Vuillemin also holds that most of the species originally included by Persoon under the genus Monilia have been shown to belong to Aspergillus, Penicillium, or Torula. Fries takes as the type of the genus, Mucor caespitosa Linn., which is the same as Monilia digitata. This, from his description and the statements of Persoon, is an Aspergillus, as the name itself would suggest. Thus there is no doubt but that Fries had an Aspergillus-like fungus in mind as the type of the genus Monilia.

Vuillemin, however, taking Monilia fructigena as the type of the genus tries to show that this is very similar to Monilia candida (M. Bonordenii Vuil.) in its process of spore formation, and in turn he accept Plaut's ('87) conclusion that Monilia candida is the same as the thrush organism, Monilia (Oidium) albicans. He bases his conclusions on the fact that the spores of Monilia fructigena are blastospores rather than conidiospores. Thus he attempts to justify placing all the yeast-like fungi of the Oidium albicans type in the genus Monilia. But anyone who has made a study of Monilia (Sclerotinia) cinerea and fructigena is familar with the fact that they produce a distinct aerial mycelium, and that the conidia are of fairly uniform size and germinate by means of a true germ tube. All of these characters are lacking in Oidium albicans. If Vuillemin's conclusions were in accord with the rules of nomenclature, and we accepted Monilia fructigena as the type of the genus, there would be sufficient basis for discarding it for the yeast-like forms under discussion. On the other hand, if the type of this genus is Aspergillus-like, then the forms under consideration could not be included.

The genus Oidium was founded by Link in 1809. Fries gives as the type of this genus Mucor leprosus Linn., and as a synonym of this Oidium aureum Link, thus accepting Link's type species. This fungus 
is well known and has a distinct septate, aerial mycelium, and sporophores, characters which serve to eliminate it from the present discussion.

The genus Blastomyces has led to great confusion in that the budding fungi are often known as blastomycetes. Though Frank created an order which he called 'Blastomycetes,' he did not have a genus of that name in the order. Costantin and Rolland ('88) created a new genus, Blastomyces, for a fungus which is not at all yeast-like in character. Gilchrist and Stokes ('96) named a budding organism isolation from a skin disease, Blastomyces dermatitidis, and Roncali ('95) also used this generic form for a budding organism isolated from a carcinoma of the ovary. The former organism is yeast-like only during a part of its life history, later forming a distinct aerial mycelium. The latter is very similar to the organisms studied in this investigation. Medical writers in general have been inclined to use this name in a loose sense for all pathogenic yeast-like fungi. The genus is tenable neither for these organisms nor for the type represented by Gilchrist and Stokes' fungus.

The genus Hormiscium, erected by Kunze and Schmidt in 1817, and used by Bonorden ('51) to include a number of the fermenting yeast-like organisms, has been emended and transferred to the Dematiaceae by Saccardo.

Cryptoccocus was erected by Kützing ('33) as a genus of the algae. He lists 1 species, Crytococcus mollis, and does not include a specific description. The generic description is as follows: "Globuli mucosi hyalini non colorati, in stratum indeterminatum muscosum facile secedens sine ordine aggregate." In a later publication he places Saccharomyces cerevisiae in this genus. Vuillemin ('01) has, unfortunately, selected this name for a genus to include all the pathogenic yeasts. Guilliermond ('12) has accepted Vuillemin's interpretation of this genus, and places in it all yeasts not forming spores which are associated with animal disease. The genus Cryptococcus is considered valid for those asporogenic yeasts which do not form a distinct septate mycelium, and will be used in the future discussion for such species.

De Beurmann and Gougerot ('09) have discussed in detail the classification of the mycoses of aninals. They call attention to the great confustion which exists, especially among medical writers, regarding the proper botanic position of the various types of budding fungi causing disease. They present a scheme of classification which includes all the described species of budding fungi associated with animal 
disease. The accompanying summary of their system includes only a discussion of the genera involved.

1. Saccharomyces, Meyen, 1838. In this are included those yeasts which have round, oval, elliptical, or elongated cells, with vegetable reproduction by budding only, and ascospore formation always present.

2. Atelosaccharomyces. de Beurmann and Gougerot, 1909 (genre provisoire). This genus, in all respects, except in the formation of ascospores, is exactly like Saccharomyces, that is, it is the 'imperfect' genus corresponding to Saccharomyces.

3. Parasaccharomyces.* de Beurmann and Gougerot, 1909. (Emend Anderson.) Similar to the preceding genus except that there are elongated cells and rudimentary mycelial threads.

4. Zymonema. De Beurmann and Gougerot, 1909. Thallus composed of a mixture of round, oval, or elliptical budding cells, and distinct, branched septate mycelial elements. The hyphae may break up into short rectangular cells as in Oidium lactis, or may form either intercalary or terminal chlamydospores.

5. Endomyces. Rees, 1870 (Emend). Thallus formed of branched, budding articles. Ascus solitary at the end of the filament and containing 4 hemispheric or reniform, hyaline ascospores.

Of the 5 genera the first and last form ascospores and their characters are well established. The 2 nd, 3 rd and 4 th genera contain the budding forms not producing ascospores, and it is with these that we are especially concerned. Atelosaccharomyces as defined by these authors corresponds to the genus Cryptococcus of Kützing, and on this account the earlier name, Cryptococcus, has been substituted in the following discussion for Atelosaccharomyces of De Beurmann and Gougerot. Parasaccharomyces, though not well defined by these authors, is evidently intended to include such forms as Monilia candida, in which the budding phase predominates, but rudimentary septate hyphae are produced. A number of species of this character were studied in the present investigation, some forming only a few unbranched elongated elements which rarely become septate, others producing a scantily branched but abundant mycelium with septate hyphae (Monilia candida). The mycelium is never aerial nor dry in character in these species. It has been thought best to accept the genus Parasaccharomyces with this more complete characterization rather than to add to the confusion by erecting another genus.

The genus Zymonema was erected by De Beurmann and Gougerot to include such species as 'Blastomyces dermatitidis' in which the

\footnotetext{
* Parasites mal classes, proches des saccharomyces. Mêmes caractères que les atelosaccharomyces, c'est-à-dire cellules rondes ou ovoides ou allongěes, bourgeonnants sans asques connues. Mais les formes de transition avec les parasites suivants (ébauches filamenteuses, formes oidiennes) sont plus marquées et indiquent l'éloignement du genre bien défini des saccharomyces.
} 
budding phase is secondary in importance, the final result of growth in culture being a markedly branched, aerial mycelium. They propose the name Zymonema Gilchristi for the organism described by Gilchrist and Stokes ('95), and more thoroughly investigated by Ricketts ('01) and others. This name should be adopted for the fungus, in order to do away with the confusion which has arisen in recent years from the use for it of such generic names as Blastomyces, Oidium, and Cryptococcus.

The accompanying key includes the genera of budding fungi, in which the budding phase is predominant. This includes not only the yeasts without spore formation, but also those developing ascospores.

\section{Key to Genera of Budding - Fungi}

I. Ascospores known:

Vegetative cells single or attached in irregular colonies, mycelium not developed, ascospores formed within isolated vegetative

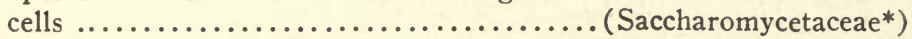

Spores globose or ovoid:

Spores on germination forming typical yeast cells :

Ascus formation preceded by the conjugation of gametes................. Zygosaccharomyces

Ascus formation not preceded by the conjugation of gametes :

Spore membrane single...........2. Saccharomyces

Spore membrane double............ 3. Saccharomycopsis

Spores on germination forming a poorly developed promycelium................ 4. Saccharomycodes

Spores pileiform or limoniform, costate.... 5. Willia

Spores hemispheric, angular or irregular in form, on germination forming an extended promycelium................6. Pichia

Vegetative cells produced predominantly by budding, but forming a mycelium under some conditions, asci terminal or intercalary, differentiated from the mycelium........... 7. Endomyces

II. Ascospores not known, i. e., Fungi imperfecti :

Heavy, dry pellicle formed on liquid mediums.. 8. Mycoderma

No distinct pellicle formed:

Vegetative cells forming a septate mycelium under exceptional conditions but predominantly budding............... 9. Parasaccharomyces

Vegetative cells formed only by budding.

Cells apiculate, limoniform............10. Pseudosaccharomyces

Cells frequently elongated into narrow, nonseptate hyphal threads...........11. Pseudomonilia

Cells typically yeast-like.............. Cryptococcus

* The genus Schizosaccharomyces, which does not bud, and the relatively unimportant genera, Monospora and Nematospora, are not included in this key. 


\section{Descriptions of New Species of Yeasts}

Over 100 cultures of unknown yeast-like fungi were studied during the present investigation. The cultural and morphologic characters of all these were studied sufficiently to demonstrate that there were few absolute duplications in the entire number of cultures. A detailed investigation of a group of these cultures has been presented in a previous section. Specific descriptions of some of these, together with a few other interesting forms, will be given. Cultures of the described species have been sent to the American Museum of Natural History, New York, the Centralstelle für Pilzenkulturen, Amsterdam, Holland, and the United States Department of Agriculture, Bureau of Plant Industry. An additional set together with dried type material has been deposited in the herbarium of the Department of Botany, University of Illinois.

\section{PSEUDOSACCHAROMYCES STEVENSI SP. NOV.}

Morphology.-In both young and old cultures the cells are narrowly elliptical, oblong, or apiculate; cytoplasm, very granular; vacuoles, not distinct except in old, swollen cells; no elongated cells or false mycelium are formed under any condition of culture. Budding occurs only at ends, by elongation and swelling of the apiculate portion. The size is $2 \times 5$ microns.* No endospores are formed. (Plate 3, Figs. 10, 11.)

Cultural Characters.-On glucose agar the streak is filiform, glistening, white, flat, and smooth. The growth is slow, and the colony becomes dirty-gray with age. In gelatin no liquefication occurs; the growth is filiform. In beerwort and sugar mediums there is slow development, with no evidence of growth except a slight sediment. The giant colonies are very small. (Plate 6, Fig. 9; Plate 8, Fig. 18.)

Physiologic Properties.-There is no fermentation of glucose, levulose, sucrose, lactose, raffinose, galactose, or maltose. No decided change in acidity occurs in these sugars, dextrin, or yeast water. There is no change in litmus milk.

The culture was isolated from human feces. (Culture 9.101; Type Specimen 1; Type Slide 9.)

\section{ZYGOSACCHAROMYCES BISPORUS SP. NOV.}

Morphology.-In young liquid cultures the cells are oval or ovate; in old cultures they assume various forms with numerous conjugating, but usually no sporulating cells. Elongated cells are common, but there is no mycelial formation. Budding occurs from end or side. The size is $4 \times 6.5$ microns. Spore formation occurs on carrot slants at room temperature. Conjugation is most common previous to spore formation, but parthenogenesis is not rare. There are 2-4 ascospores, most commonly 2. (Plate 4, Fig. 8.)

Cultural Characters.-On glucose agar the growth is spreading, dull, flat, and white; later it becomes brownish with small, scattered, wart-like prominences and more glistening surface. There is a filiform growth in gelatin stab and liquefication in beerwort gelatin in 3 weeks. Pellicle is present on beerwort and some sugar mediums. Giant colonies may be seen in Plate 6, Figure 6.

* The size given is not the average of a large number of measurements, but is the result of an attempt to select a single cell which will represent the size and proportions of the most numerous cells of a fairly uniform character. This plan is believed to give more definite results than could be obtained by measuring numerous cells and averaging these. This conclusion is based on a study of both methods. 
Physiologic Properties.-It does not ferment glucose, sucrose, levulose, maltose, galactose, or raffinose. No decided change in acidity occurs in these mediums. There is no change in litmus milk.

The culture was isolated from human feces. (Culture 11.501; Type Specimen 3; Type Slide 11.5.)

\section{CRYPTOCOCCUS VERRUCOSUS SP. NOV.}

Morphology.-In young liquid culture the cells are oblong, narrowly elliptical or oblong-elongated; in old cultures elongated cells are common, with several 'oil' globules in each cell. The size is $3 \times 9$ microns. Budding occurs from shoulders, ends, or sides. No endospores are formed. (Plate 5, Figs. 1, 2.)

Cultural Characters.- On glucose agar slant there is at first an even, filiform, glistening, white, smooth growth; later it becomes dull, brittle, verrucose, and pulvinate. On carrot slant the growth is more profuse, with verrucose character more pronounced, and with chalky-white surface. There is a filiform or nodose growth in gelatin stab, with no liquefaction. On sugar mediums and beerwort, after 2 days, a few small, white patches appear on the surface, later becoming larger, dry, and very firm; at first they remain separate, but later coalesce. Giant colonies may be seen in Plate 6, Figure 10, and in Plate 8, Figure 14.

Physiologic Properties.-It does not ferment glucose, levulose, sucrose, maltose, galactose, lactose, or raffinose. No decided change in acidity occurs in these sugars. Litmus milk becomes very slightly alkaline after several weeks.

The culture was isolated from human feces. (Culture 172.1; Type Specimen 2; Type Slide 172.)

The dry brittle character of the colonies on solid mediums, the formation of the isolated, white patches on all liquid mediums, and the peculiar type of cells, clearly distinguishes this yeast from any other studied.

\section{CRYPTŐCOCCUS AGGREGATUS SP. NOV,}

Morphology.-In both young and old cultures the cells are mostly globular or slightly oval. No elongated cells are formed. Budding occurs from any point on the cell, usually several buds arise from each cell; in old cultures buds are commonly formed in large numbers àbout a single enlarged cell. The size is 3.5 microns. (Plate 4, Figs. 1, 2.)

Cultural Characters.-On glucose agar slant the growth is filiform, convex, glistening, smooth, chalk-white, and firm. In old cultures the surface remains smooth, with even edges and no darkening in color. Filiform, later nodose growth occurs in gelatin stab, with no liquefaction. No pellicle or ring is formed in beerwort or liquid sugar mediums. The surface of the giant colonies on glucose agar plates remains remarkably smooth, only dim, concentric lines appearing. (Plate 6, Fig. 12; Plate 8, Fig. 19.)

Physiologic Properties.-There is no fermentation in glucose, sucrose, levulose, maltose, galactose, lactose, or raffinose yeast water. No decided change in acidity occurs in these sugar mediums. Litmus milk becomes very slightly alkaline after 3 weeks.

The culture was isolated from human feces (Culture 215.103; Type Specimen 3; Type Slide 215).

Two other cultures, 215.101 and 215.102 , isolated from the same person were compared with the foregoing species and found to be identical. The isolations were made from the same sample of feces but from different colonies. 
CRYPTOCOCCUS OVOIDEUS SP. NOV.

Morphology.-Cells in young cultures are round or oval, and fairly uniform in size and shape; in old culture cells are oval or broadly elliptical, varying markedly in size and with few budding cells. There are no elongated cells or hyphal elements. The size is $3.5 \times 4.5$ microns. (Plate 3, Figs. 1, 2.)

Cultural Characters.-On glucose agar the streak is filiform, slightly raised, glistening, smooth, and chalk-white. The growth is slow and there is little change in old cultures. There is a filiform growth in gelatin stab, with no liquefaction. No pellicle or ring is present in beerwort or in liquid sugar mediums. Giant colonies may be seen in Plate 6, Fig. 17, and in Plate 8, Fig. 20.

Physiologic Characters.-There is slight fermentation of glucose, levulose, and sucrose. This occurs only after a week and the production of gas is never over 10 per cent. of the closed arm of the tube. No decided change in acidity occurs in sugar mediums. There is no change in litmus milk.

The culture was isolated from human feces. (Culture 137.101; Type Specimen 5; Type Slide 137.1.)

This species is very similar in many of its characters to Culture 170.101. The latter, however, ferments glucose and levulose very rapidly and completely. Both of these cultures are slow growing, very smooth, and remain white and even-edged in very old cultures. The surface elevation is not so decidedly convex as in most yeasts of the white, glistening type.

\section{CRYPTOCOCCUS GLABRATUS SP. NOV.}

Morphology.-Cells in young cultures are oval or elliptical, and fairly uniform in size and shape; in old cultures cells are round, oval, or elliptical, and more variable in form and size. Budding occurs from the ends or shoulders of the oval and elliptical cells. There are no elongated cells or hyphal elements. The size is $3 \times 4.5$ microns. (Plate 3 , Fig. 12.)

Cultural Characters. - On glucose agar the streak is filiform, glistening, raised, smooth, and chalk-white. In old cultures the surface remains smooth and the edge entire. There is a slow growth on all solid mediums; liquid mediums remain clear with little evidence of growth, and no pellicle or ring formation is present. A giant colony may be seen in Plate 8, Fig. 21.

Physiologic Characters.-There is rapid fermentation of glucose and levulose. Other sugars are not fermented. Litmus milk becomes only slightly alkaline. No decided change in acid reaction occurs in sugar mediums. Gelatin is not liquefied.

The culture was isolated from human feces. (Culture 170.101; Type Specimen 6; Type Slide 170.)

This species differs in few respects from Cryptococcus ovoideus. The cells are more elliptical and the fermentation reactions are unlike.

\section{MYCODERMA MONOSA SP. NOV.}

Morphology.-Cells in young cultures are elliptical or narrowly elliptical; in old cultures cells are of various forms, predominantly elliptical, with numerous elongated and irregular forms. Rows of elongated cells in old cultures form a false mycelial development. No true septation is observed. Budding occurs from the ends or from shoulders of the young cells. The size is $2 \times 5.5$ microns. (Plate 3, Figs. 14, 15.)

Cultural Characters.-On all agar slants the streak is spreading, dull, white, flat, and becoming gray with age. A heavy dull pellicle is formed within 24-48 
hours on all liquid sugar mediums and on beerwort. There is a villous growth along stab in gelatin. Giant colonies may be seen in Plate 7, Fig. 12, and in Plate 8, Fig. 10.

Physiologic Properties.-Glucose and levulose ferment readily. There is no change in litmus milk. Sugar mediums, with an original acidity of -1 , become less acid after 1 week.

The culture was isolated from human feces. (Culture 141.101; Type Specimen 7; Type Slide 141.1.)

\section{MYCODERMA RUGOSA SP. NOV.}

Morphology.-Cells in young cultures are elliptical, oblong, elongated, or somewhat irregular; in old cultures the cells on the surface of the medium are oblong, ovate, or elongated; beneath the surface very long, narrow cells of hyphal character are produced by the elongation of the bud at the distal end of another elongated cell. No septate mycelium is formed. Budding in young cell occurs from end or shoulder. The size is $3 \times 6.5$ microns. (Plate 3, Figs. 8, 9.)

Cultural Characters.-On glucose agar slant the streak is white, dull, and flat, but not spreading; later the surface becomes glistening and decidedly rugose and pitted. Bushy growths may extend downward into the agar at points along the streak. There is a rapid villous development in gelatin stab cultures. A heavy pellicle is formed in sugar mediums and beerwort. Giant colonies are very distinctive. (Plate 7, Fig. 5.)

Physiologic Characters.-No sugars are fermented; there is no change in litmus milk.

The culture was isolated from human feces. (Culture 128.1; Type Specimen 8; Type Slide 128.)

This Mycoderma is not distinguishable from several other species, for example, M. cerevisiae, as far as the morphologic and physiologic characters enumerated are concerned. An examination of photographs of the giant colonies of various Mycoderma species revealed the fact that none of these species produce the peculiar rugose-pitted type formed by the foregoing species. The production of such type of growth is not confined to giant colonies on glucose agar, but is present on slants of glucose and beerwort agar.

PARASACCHAROMYCES ASHFORDI SP. NOV.

Morphology.-In young cultures cells are round or slightly oval; in old cultures cells are of many forms: oval, elongated, elliptical, round, or irregular; giant cells are common. Septate mycelium develops in gelatin hanging-drop and in old cultures. Budding occurs from any point on the young cells, but usually near the ends of articles in old cultures. The size is $4.5 \times 5$ microns. (Plate 4, Figs. 4, 5; Plate 5, Figs. 11, 12.)

Cultural Characters.-On glucose agar the streak is filiform, raised, glistening, chalk-white and smooth; later the central portion may become rugose or pitted; the edge of the streak may remain entire or may become decidedly filamentous, due to the outward growing hyphal elements under the surface of the medium (Plate 4, Fig. 5a). There is a growth in gelatin stab at first filiform, later it develops scattered, bushy clusters of filaments. In liquid sugar mediums and beerwort a very evident ring formation occurs; no pellicle is present. Giant colonies may be seen in Plate 7, Fig. 8, and in Plate 8, Figs. 7, 8. 
Physiologic Properties.-It ferments glucose, maltose, and levulose; occasionally sucrose and galactose are fermented. Yeast-water sugar mediums, with an initial acidity of +1 , become more alkaline (Table 6 , Culture 2.501). Litmus milk is rendered alkaline in 2 weeks, but is not clotted. Gelatin is rarely liquefied.

The culture was isolated from a sprue patient by Dr. B. K. Ashford in Porto Rico. (Culture D; Culture 2.501 was pronounced by Dr. Ashford to be identical with his organism*; Type Specimen 4; Type Slide 2.5.)

This species strongly resembles the fungus variously called Oidium albicans, Monilia albicans, and Endomyces albicans: Castellani ('16) has, however, reserved the name Monilia albicans for a species which always clots milk and liquefies gelatin. Monilia albicans, Oidium albicans and Endomyces albicans are synonyms, and if Vaillimin's ('99) results are accepted and are of general application to all of these, the correct name for the species is Endomyces albicans, since he states that this species forms asci after the manner of other species of the genus Endomyces. Since all efforts to develop the perfect stage of the sprue organism, both by Dr. Ashford and myself, ended in failure and since it differs in many of its physiologic characters from the typical Endomyces albicans, it has been thought best to give it specific rank rather than to regard it as a variety of Endomyces albicans.

PARASACCHAROMYCES THOMASI SP. NOV.

Morphology._-In young cultures, cells are elliptical or ovate; in old cultures, surface cells are round, oval, elliptical, or elongated; submedial cells form a distinct mycelium mostly by elongation of cells produced by budding. There is occasional septation in gelatin hanging-drop. Budding occurs from ends or shoulders. The size is $3.5 \times 5$ microns. (Plate 5, Figs. 4, 5.)

Cultural Characters.- On glucose agar the streak is, at first, white, glistening, convex, and smooth; later the surface becomes rugose with a decidedly elevated ridge down the center. Beneath the surface of the medium the radiating hyphae form a villous fringe. In beerwort and liquid sugar mediums no pellicle or ring is present. In gelatin-stab cultures the growth is finely villous. Giant colonies in beerwort gelatin are decidedly yellow in color and otherwise very characteristic. (Plate 6, Fig. 4; Plate 8, Fig. 12.)

Physiologic Properties.- Slow fermentation of glucose, levulose, and maltose. In litmus milk there is a decided alkaline reaction.

The culture was isolated from human feces. (Culture 147.103; Type Specimen 10; Type Slide 147.)

This species is similar to Parasaccharomyces Ashfordi in its physiologic properties. It differs mainly in its morphologic characters and the type of giant colonies produced. The yellow, rugose colony in beerwort gelatin is especially characteristic and easily distinguishes in this species from P. Ashfordi.

\section{SUMMARY AND CONCLUSIONS}

Yeast-like fungi are commonly found in the intestinal tract of man. They are of many species and, for the most part, such types as are commonly present in nature and known as 'wild yeasts.' It is probable that these yeasts are ingested with the food.

*Letter, Dec. 6, 1916. 
The feces of persons suffering from gastro-intestinal disorders of various types do not yield a larger number of yeasts than those from healthy persons. There is no one species commonly present in the intestinal tract of either healthy persons or those suffering from gastrointestinal troubles.

In a case diagnosed by highly competent clinicians as sprue, yeastlike organisms of a single species and in great numbers were constantly present. This species is the same as the sprue organism isolated by Ashford.

Nonpathogenic yeasts, when fed in mass, pass through the alimentary tract in a living condition and may be found in great numbers in the feces. They do not cause serious inconvenience when fed alone; and are not retained longer than the ingested food.

The sprue organism, when ingested after being in culture for several months, is not able to cause the disease but is retained in the intestinal tract for a longer time than in the case of the nonpathogenic forms.

The pathogenic yeasts, for the most part, are easily distinguished from the yeast-like fungi isolated from the digestive tract. None of the yeasts isolated from healthy persons or from those suffering temporary intestinal disturbances were identical with the pathogenic yeasts studied.

Generic separation among the yeasts which do not form ascospores is based on the presence or absence and relative predominance of a septate mycelial phase in the life history of the organism, together with the type of budding and striking cultural characters. The genera to which the budding asporogenic fungi belong are: Cryptococcus, Parasaccharomyces, Pseudosaccharomyces, Pseudomonilia, Mycoderma, and Zymonema.

On account of the wide morphologic and cultural variations within a single species, the separation of species is based on the combination of morphologic, cultural, and physiologic characters. The necessity of a standard method of procedure similar to that of the bacteriologists for the separation of species is recognized.

The yeast-like fungus associated with sprue is similar in many of its characters to Endomyces albicans and is possibly identical with the yeast commonly found causing thrush in children.

The sprue organism (Parasaccharomyces Ashfordi sp. nov.) is easily distinguished from the 'wild yeasts' commonly found in the intestinal tract by its reactions in sugar mediums and milk; and cultural characters, such as the peculiar growth in.gelatin-stab cultures and the formation of septate mycelium in gelatin hanging-drop cultures. No 
one of these characters when taken alone is sufficient to identify the species and any or all of them vary under some conditions.

Fourteen cultures isolated from the intestinal tract were carefully studied and compared with known species. Of these, 11 were evidently different and distinct species, while 3 were sufficiently like Parasaccharomyces candida (Monilia candida Bon.) to warrant placing them in this species.

I gratefully acknowledge the very helpful assistance of Dr. F. L. Stevens, Professor of Plant Pathology, University of Illinois, throughout the preparation of this thesis. I wish also to express my appreciation of the suggestions made by Prof. William Trelease, Head of the Department of Botany, University of Illinois, concerning the taxonomic questions involved. Thanks are also due Dr. H. D. Singer, Director of the State Psychopathic Institute, Dr. B. K. Ashford, of the Institute of Tropical Medicine and Hygiene, San Juan, Porto Rico, and others who have furnished material and cultures for this investigation.

\section{REFERENCES}

Alwood, W. B.: Proc. Am. Assn. Adv. Sci., 1898, 47, p. 422.

Ashford, B. K. ('15a): Am. Jour. Trop. Dis. and Prev. Med., 1915, 3, p. 32.

Ashford, B. K. ('15b): Jour. Am. Med. Assn., 1915, 44, p. 810.

Ashford, B. K. ('15c): Ibid., p. 1893.

Ashford, B. K. ('15d) : Am. Jour. Med. Sc., 1915, 150, p. 680.

Ashford, B. K. ('16): Ibid., p. 520.

Bahr, P. N.: Jour. Trop. Med., 1914, 17, p. 203.

de Bary, A.: Comparative Morphology and Biology of the Fungi, Mycetozoa, and Bacteria, 1887.

Bassoe, P.: Jour. Infect. Dis., 1906, 3, p. 91.

de Beurmann, L., and Gougerot, H.: Bull. et mém. Soc. méd. d. hôp. de Paris, 1909, 28, pp. 222, 250.

Binaghi, R.: Ztschr. f. Hyg. u. Infectionskrankh., 1896, 23, p. 283.

Binot, J.: See Blanchard, Schwartz, and Binot.

Birch-Hirchfeld ('75) : Jahresb. d. Gesellsch. f. Nat.- u. Heilk. in Dresd., 1875 , p. 31 .

Blanchard, R., Schwartz, E., and Binot, J.: Bull. de l'Acad. de méd., Paris, 1903,49 , p. 415.

Böhm: Die kranke Darmschleimhaut in der Asiatischen Cholera, Berlin, 1828.

Bonorden, H. F.: Handbuch der Allgemeinen Mycologie, Stuttgart, 1851.

Busse, O. ('95) : Arch. f. path. Anat. u. Physiol., 1895, 140, p. 23.

Busse, O. ('96) : Centralbl. f. Bakteriol., I, 1896, 20, p. 236.

Busse, O. ('03) : Cited in Kolle and Wassermann, Handb. d. path. Mikroorg., 1903,1, p. 660.

Cao, G.: Ztschr. f. Hyg. u. Infectionskrankh., 1900, 39, p. 282.

Casagrandi, O. ('98) : Centralbl. f. Bakteriol., I, 1898, 24, p. 758.

Casagrandi, O. ('98): Ibid., p. 759.

Castellani, A. ('11) : Centralbl. f. Bakteriol., I, 1911, 58, p. 236.

Castellani, A. ('12) : Brit. Med. Jour., 1912, p. 1208.

Castellani, A. ('13): Jour. Trop. Med., 1913, 16, p. 102.

Castellani, A. ('14): Ibid., 1914, 17, p. 305. 
Castellani, A. ('16) : Ann. d. l'Inst. Pasteur, 1916, Par. 30, p. 149.

Castellani, A., and Low, C. C.: Jour. Trop. Med., 1913, 16, p. 33. 1913.

Castellani, A., and Chalmers, A. J.: Manual of Tropical Medicine, London,

Costantin, J., and Rolland, L.: Bull. Soc. mycol. de France, 1888, 4, p. 153.

Curtis, F.: Ann. d. l'Inst. Pasteur, 1896, Par. 10, p. 449.

Demme, R.: Jubile de Ed. Henoch, Berlin, 1890. Abstract in Baumgarten's Jahresb., 1891, 7, p. 378.

Emig, W. H.: Ann. Missouri Botan. Garden, 1916, 3, p. 243.

Foulerton, A. C. R.: Jour. Path. and Bacteriol., 1899, 6, p. 37.

Frank, A. B.: In Leunis' Synopsis der drei Naturreiche, Ed. 3, Hanover, 1886, Pt. 2, Botanik, 3, p. 613.

Fries, E.: Systema Mycologicum, Grypiswaldeae, 1821-1832.

Gedoelst, L.: Le champignons parasites de l'homme' et des animaux domestiques, Brussels, 1902.

Geiger, A.: Centralbl. f. Bakteriol., II, 1910, 27, p. 97.

Gilchrist, T. C., and Stokes, R. ('96) : Bull. John Hopkins Hosp., 1896, 8, p. 129.

Gilchrist, T. C., and Stokes, R. ('98): Jour. Exper. Med., 1898, 3, p. 53.

Grawitz, P.: Virchows Arch. f. path. Anat., 1877, 70, p. 547.

Grover, A. L.: Jour. Infect. Dis., 1916, 19, p. 88.

Guéguen, F.: Les champignons parasites de l'homme et des animaux, Paris, 1904.

Guilliermond, A.: Les Levures, Paris, 1912.

Hansen, E. C. ('95) : Ann. Bot., 1895, 9, p. 549.

Hansen, E. C. ('04): Centralbl. f. Bakteriol., II, 1904, 12, p. 528.

Hesler, L. R.: Cornell Agr. Exp. Sta. Bull. 379, 1916.

Klöcker, A. ('15) : Centralbl. f. Bakteriol., II, 1915, 43, p. 368.

Klöcker, A. ('12) : Centralbl. f. Bakteriol., II, 1912, 35, p. 375.

Kohlbrugge, J. H. I.: Arch. f. Schiff- u. Tropen Hyg., 1901, 5, p. 394.

Kützing, F. T. ('33): Linnaea, 1833, 8, p. 365.

Kützing, F. T. ('43) : Phycologia generalis, Leipzig, 1843.

Le Dantec, A.: Compt. rend. Soc. de biol., 1908, 64, p. 1066.

Leopold, G.: Arch. f. Gynäk., 1900, 61, p. 77.

Lindner, B.: Mikroskopische Betreibskontrolle in den Gährungsgewerben, Berlin, 1905.

Loeb, L., Moore, G. T., and Fleisher, M. S.: Centralbl. f. Bakteriol., I, 1913, 67 , p. 450.

Lutz, L., and Guéguen, F.: Bull. Soc. mycol. de France, 1901, 17, p. 83.

Maffuci, A., and Sirleo, L.: Ztschr. f. Hyg. u. Infectionskrankh., 1898, 27, p. 1.

Neumayer, J.: Arch. f. Hyg., 1891, 12, p. 1.

Persoon, C. H.: Mycologia Europeae, Erlangae, 1822-1828.

Plaut, H. ('85) : Beiträge zur systematischen Stellung des Soorpilzes in der Botanik, Leipzig, 1885.

Plaut, H. ('87) : Neue Beiträge zur systematischen Stellung des Soorpilzes in der Botanik, Leipzig, 1887.

Plaut, H. ('03a) : Cited in Kolle and Wassermann, Handb. d. path. mikroorg., 1903, 1, p. 626.

Plaut, H. ('03b) : Ibid., p. 583.

Rabinowitsch, Lydia: Ztschr. f. Hyg. u. Infectionskrankh., 1895, 21, p. 11.

Raum, J.: Ztschr. f. Hyg. u. Infectionskrankh., 1891, 10, p. 1. 
Ricketts, H. T.: Jour. Med. Research, 1901, 6, p. 375.

Roncali, D. B. ('95) : Centralbi. f. Bakteriol., 1, 1895, 18, p. 353.

Roncali, D. B. ('98): Jour. Path. and Bacteriol., 1898, 5, p. 1.

Samburger, F.: Arch. bohêmes de Méd. Clin., 1905, 5.

San Felice, F.: Ztschr. f. Hyg. u. Infectionskrankh., 189.5, 21, p. 32; 1896, 22 ,

p. $171 ; 1897,26$, p. $298,1898,29$, p. $463 ; 1903,44$, p. 364.

Simon, C. E.: Am. Jour. Med. Sc., 1917, 153, p. 231.

Stober, A. M.: Arch. Int. Med., 1914, 13, p. 509.

Sumstine, D. R.: Mycolia, 1913, 5, p. 45.

Turpin, P. J. F.: Compt. rend. Acad. d. sc., 1838, 7, p. 369.

Vuillemin, P. ('98) : Compt. rend. acad. d. sc., 1898, 127, p. 630.

Vuillemin, P. ('99) : Rev. mycol., 1899, 21, p. 43.

Vuillemin, P. ('06) : Rev. gén. d. sci. pures et appliq., 1906, 17, p. 214.

Vuillemin, P. ('01): Ibid., 190ı, 12, p. 731.

Vuillemin, P. ('10): Ibid., 1910, 21, p. 148.

Vuillemin, P. ('11): Bull. Soc. mycol. de France, 1911, 27, p. 137.

Wade, H. W., and Bel, G. S.: Arch. Int. Med., 1916, 18, p. 103.

Will, H. ('03-'08) : Centralb. f. Bakteriol., II, 1903, 10, p. 689; 1906, 17, pp.

$1,75,137,331,428,604,693 ; 1908,21$, pp. 386, 459.

Will, H. ('10) : Ibid., 1910, 28, p. 1.

Will, H. ('12) : Ibid., 1912, 35, p. 81.

Will, H. ('15) : Ibid., 1915, 44, p. 225.

Will, H., and Leberle, H. ('11) : Ibid., 1911, 29, p. 609.

Wilson, L. B.: St. Paul Med. Jour., 1904, 6, p. 649.

Wood, E. J.: Am. Jour. Med. Sc., 1915, 150, p. 692. 


\section{Plate 3}

Fig. 1. Cryptococcus ovoideus sp. nov. Cells from a young, beerwort culture.

Fig. 2. Cryptococcus ovoideus sp. nov. Cells from an old, glucose agar culture.

FIG. 3. Culture 141.201. a, Elongated cells with groups of buds. From beneath the medium in an old, glucose agar culture. b, Cells from the surface of the medium.

FIG. 4. Parasaccharomyces candida comb. nov. Cells from young, beerwort culture (Culture 229).

FIG. 5. Parasaccharomyces candida comb. nov. a, Elongated cells developed in old, agar culture beneath the surface of the medium. The attached globular cells have large refractive globules filling most of the cell interior. b, Cells from surface of old culture showing large refractive globules.

FIg. 6. Saccharomyces hominis Busse. Cells from young, beerwort culture showing peculiar type of budding.

FIg. 7. Saccharomyces hominis Busse. Cells from old culture showing a1 b the numerous large granules usually present in old cells.

Fig. 8. Mycoderma rugosa sp. nov. Budding cells from young, beerwort culture.

Fig. 9. Mycoderma rugosa sp. nov. Cells from old agar culture.

FIG. 10. Pseudosaccharomyces Stevensi sp. nov. Cells from young, beerwort culture.

Fig. 11. Pseudosaccharomyces Stevensi sp. nov. Cells from old agar slant culture.

Fig. 12. Cryptococcus glabratus sp. nov. Cells from young, beerwort gelatin culture.

FIG. 13. Parasaccharomyces candida comb. nov. Budding cells from young, beerwort culture. (Culture No. 152.)

Fig. 14. Mycoderma monosa sp. nov. Cells from young, beerwort culture.

FIG. 15. Mycoderma monosa sp. nov. Cells from old, agar culture. 
Plate 3

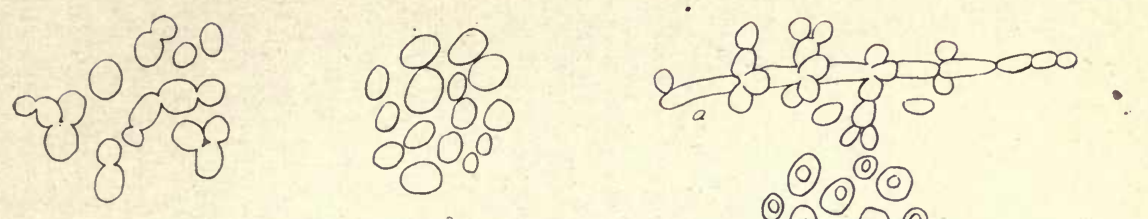

$$
\begin{aligned}
& \text { ๑ே@ }
\end{aligned}
$$

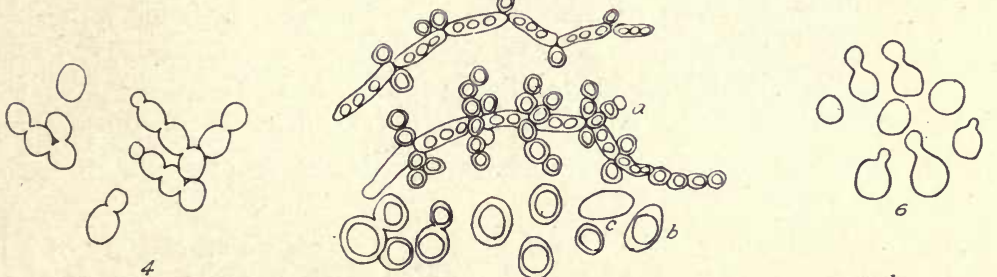

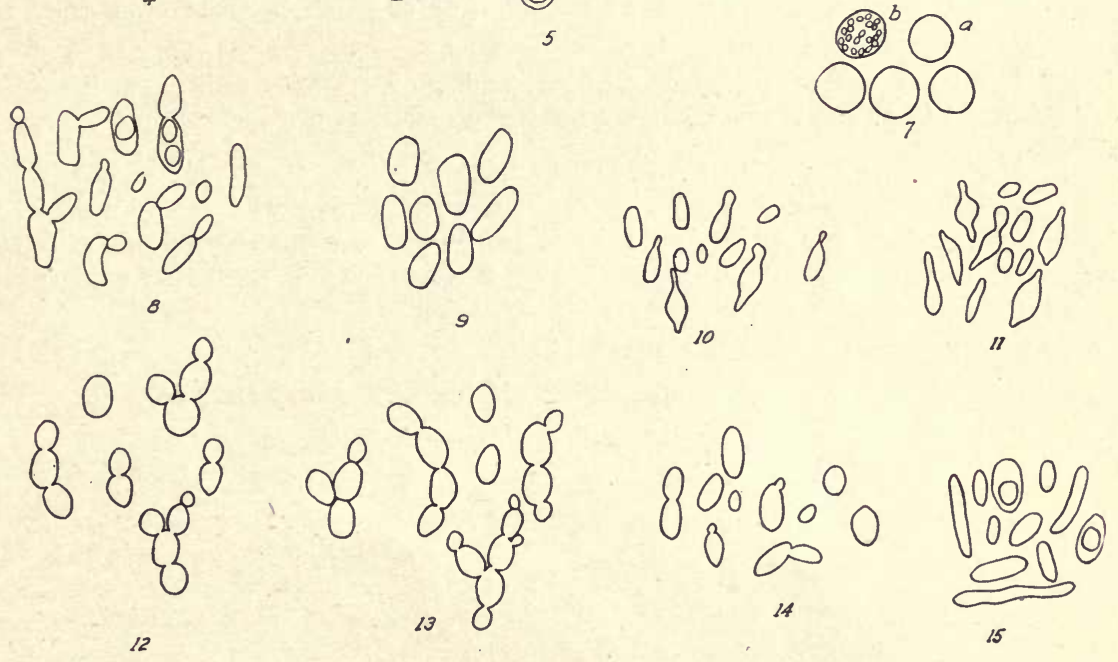




\section{Plate 4}

Fig. 1. Cryptococcus aggregatus sp. nov. Budding cells from young, beerwort culture.

FIG. 2. Cryptococcus aggregatus sp. nov. Cells from old, agar cultures, showing peculiar aggregation of buds about the enlarged, globular cells.

Fig. 3. Parasaccharomyces candida comb. nov. a, Portion of septate mycelium from beneath the surface of the medium. b, Cells from the surface of old, agar cultures. (Culture from Centralstelle für Pilzkulturen, Amsterdam.)

Fig. 4. Parasaccharomyces Ashfordi sp. nov. Cells from young, beerwort culture. (Culture D from Dr. Ashford.)

Fig. 5. Parasaccharomyces Ashfordi sp. nov. a, Moniliform clusters of cells developed beneath the surface of an old agar culture. b, Cells from the surface of the same culture.

FIG. 6. Parasaccharomyces candida comb. nov. Young cells from beerwort culture. (Culture from Centralstelle für Pilzkulturen, Amsterdam.)

FIG. 7. Zygosaccharomyces bisporus sp. nov. Cells from agar slant culture.

Fig. 8. Zygosaccharomyces bisporus sp. nov. a, Typical form of cells from old, agar slant. b, Conjugating cells which do not develop ascospores. c, Ascospore development without conjugation. d, Ascospore development as a result of conjugation. b, c, and d from carrot slant.

FIg. 9. Young cells of Culture 138.102.

FIG. 10. Saccharomyces ellipsoideus Hansen. From young culture.

FIg. 11. Saccharomyces ellipsoideus Hansen. From old culture.

Fig. 12. Old cells of Culture 138.102 . 
Plate 4

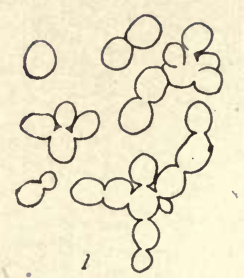

080
788
7.88
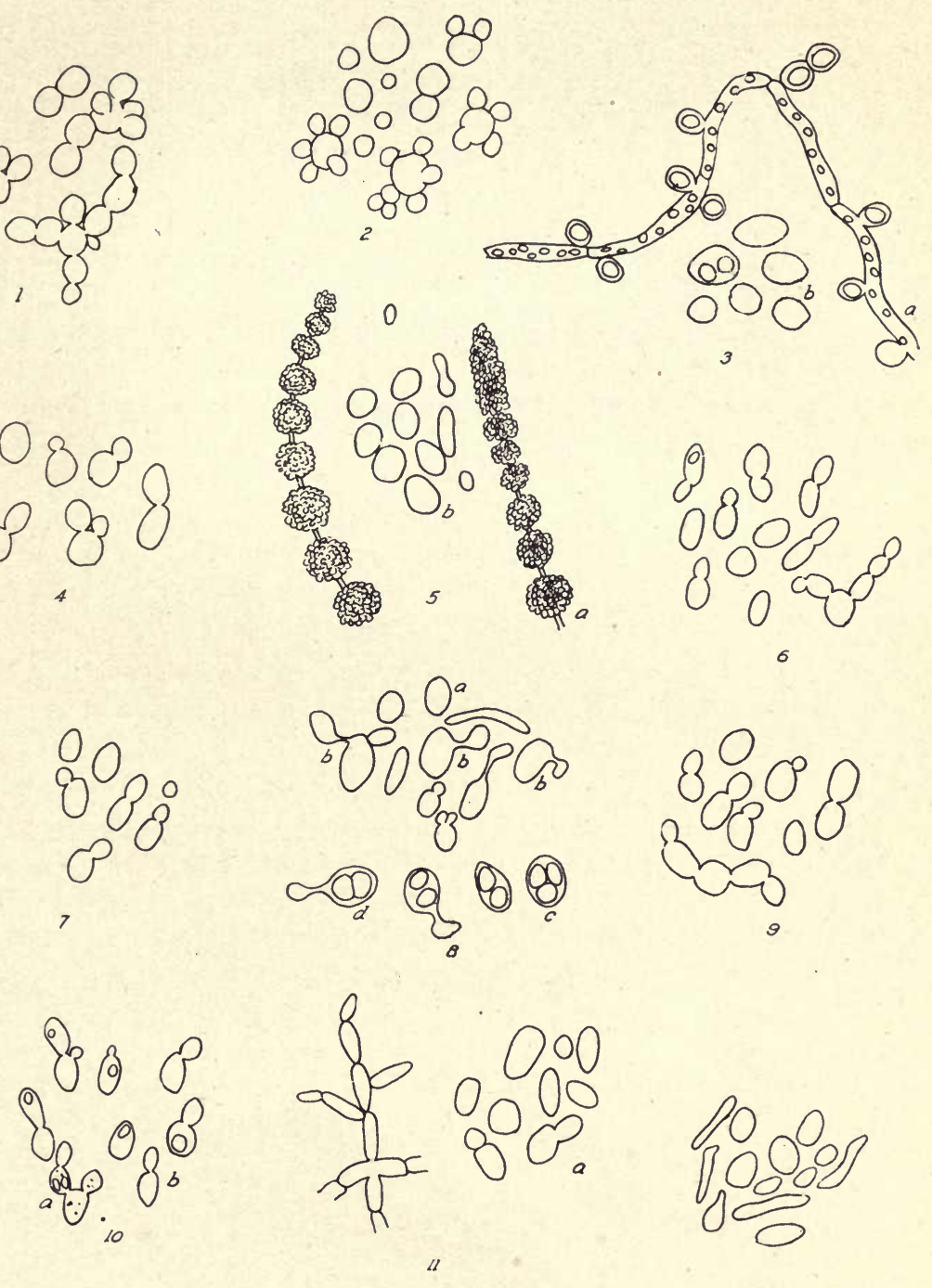


\section{Plate 5}

Fig. 1. Cryptococcus verrucosus sp. nov. Budding cells from a young, beerwort culture.

FIg. 2. Cryptococcus verrucosus sp. nov. From old, agar culture showing the pronounced granular condition.

Fig. 3. Culture 141.201. Cells from young, beerwort culture.

FIG. 4. Parasaccharomyces Thomasi sp. nov. Cells from young, beerwort culture.

FIG. 5. Parasaccharomyces Thomasi sp. nov. a, Elongated cells forming a false mycelium beneath the surface of the agar slant. The elongated cells are formed by the elongation of terminal buds. b, Cells from.surface of same culture.

FIG. 6. Parasaccharomyces candida comb. nov. (Culture 158).

FIG. 7. Culture 141.102. Cells from young, beerwort culture.

FIG. 8. Oidium albicans. Cells from young, beerwort culture (Culture from St. Thomas Hospital, London).

FIG. 9. Oidium albicans. Cells from surface of old, agar culture.

FIG. 10. Group of yeast cells from a culture of Parasaccharomyces Ashfordi showing the great variation in form and size that occurs in a single field of the microscope.

Fig. 11. Parasaccharomyces Ashfordi sp. nov. Young cells from Culture 2.501.

Fig. 12. Parasaccharomyces Ashfordi sp. nov. Old cells from surface of agar streak of Culture 2.501.

FIG. 13. Septation in the hyphae of Parasaccharomyces candida. From gelatin hanging-drop of Culture 152 . 
Plate 5

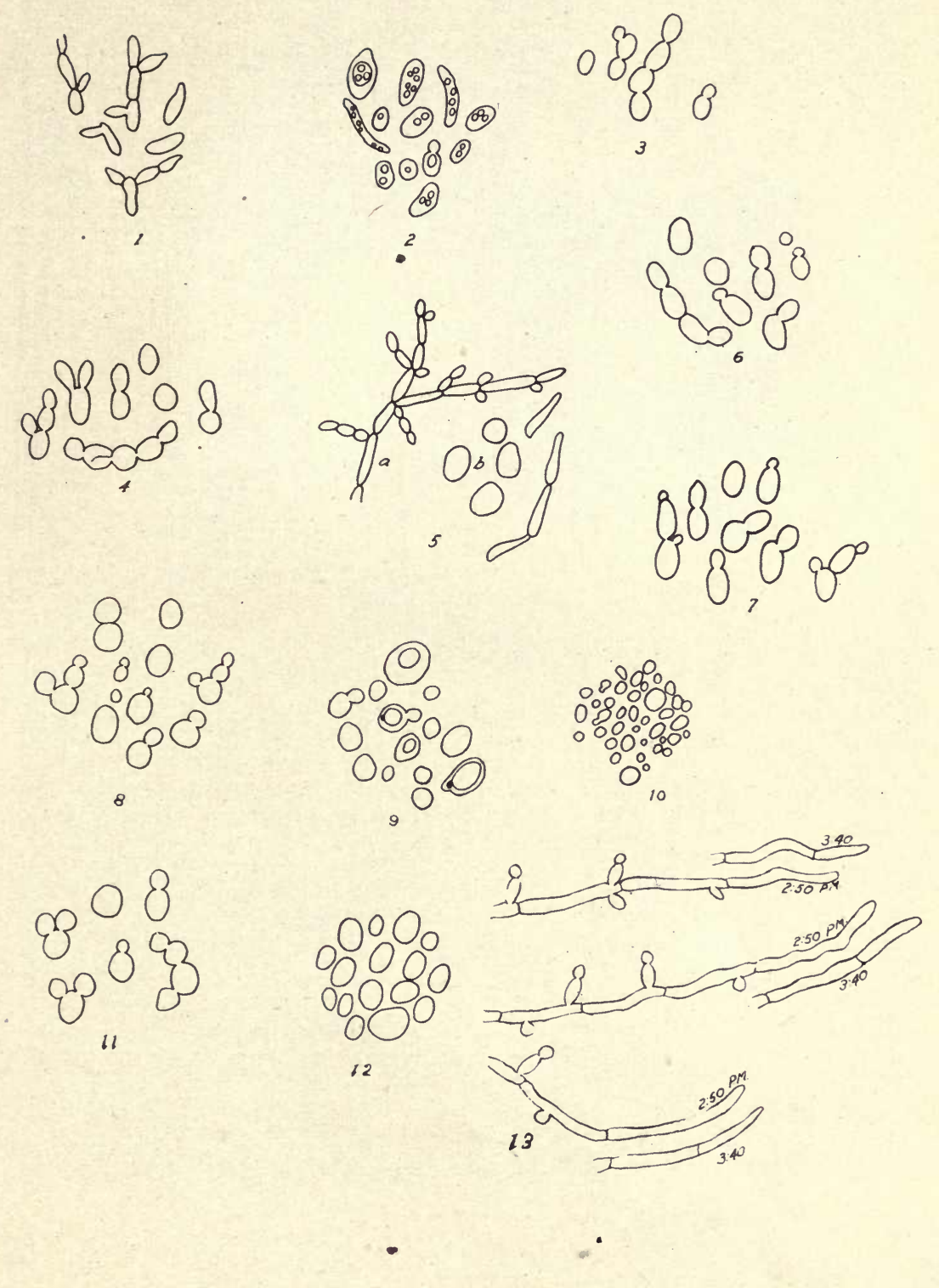




\section{Plate 6}

FIG. 1. Giant colony of Culture 10.102 on glucose agar.

FIG. 2. Giant colony of Culture 141.102 on glucose agar.

Fig. 3. Giant colony of Parasaccharomyces candida comb. nov. on dextrose agar. (Culture 229.)

FIG. 4. Giant colony of Parasaccharomyces Thomasi sp. nov. on glucose agar.

Fig. 5. Giant colony of Culture 166.102 on glucose agar.

FIG. 6. Giant colony of Zygosaccharomyces bisporus sp. nov. on glucose agar.

FIG. 7. Giant colony of Culture 167 on glucose agar.

FIG. 8. Giant colony of Culture 139.201 on glucose agar.

FIG. 9. Giant colony of Pseudosaccharomyces Stevensi sp. nov. on glucose agar.

Fig. 10. Giant colony of Cryptococcus verrucosus sp. nov. on glucose agar.

FIG. 11. Giant colony of Culture 105, on glucose agar.

Fig. 12. Giant colony of Cryptococcus aggregatus sp. nov. on glucose agar.

FIG. 13. Giant colony of Culture 147.102 on glucose agar. This is one of the pink types of yeasts.

FIG. 14. Giant colony of Oidium albicans on glucose agar. The rugose region between the inner and outer ring became more broken a few days after this photograph was taken.

FIG. 15. Giant colony of Culture 239.101 on glucose agar.

FIG. 16. Giant colony of Culture 11.901 on glucose agar.

FIG. 17. Giant colony of Cryptococcus ovoideus sp. nov. on glucose agar. 
Plate 6

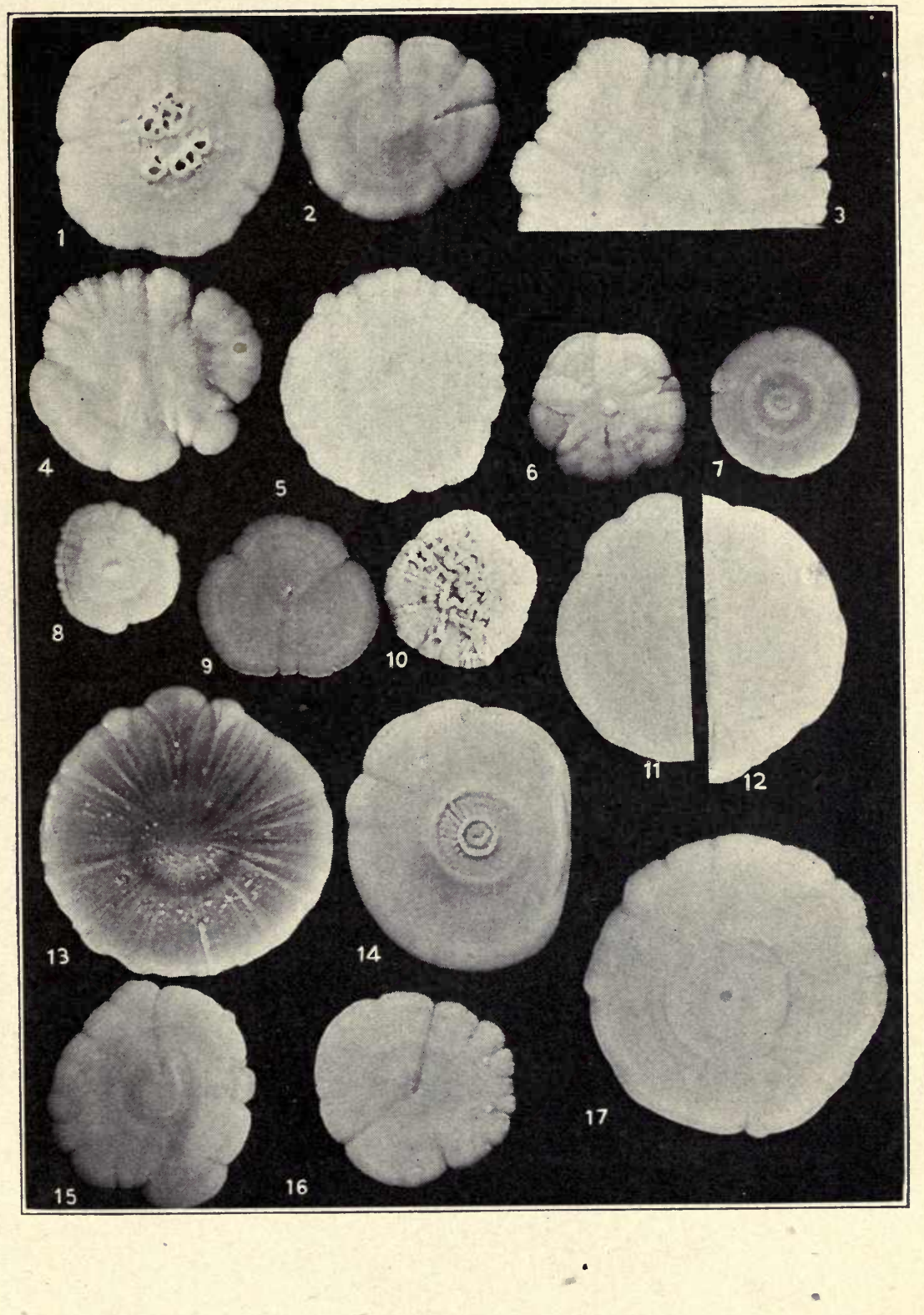




\section{Plate 7}

Fig. 1. Giant colony of Culture 138.101 on glucose agar.

FIG. 2. Giant colony of Culture 139.101 on glucose agar.

FIG. 3. Giant colony of Culture 146 on glucose agar.

Fig. 4. Giant colony of Saccharomyces cerevisiae Meyen on glucose agar.

Fig. 5. Giant colony of Mycoderma rugosa sp. nov. on glucose agar.

Fig. 6. Giant colony of Parasaccharomyces candida comb. nov. on glucose agar. (Culture 152.)

FIG. 7. Giant colony of Culture 11.701 on glucose agar.

FIG. 8. Giant colony of Parasaccharomyces Ashfordi sp. nov. on glucose agar. (Culture 2.501.)

Fig. 9. Giant colony of Culture 215.101 on glucose agar. (Probably Cryptococcus aggregatus.)

Fig. 10. Giant colony of Culture 42 on glucose agar.

FIG. 11. Giant colony of Culture 120.102 on glucose agar.

Fig. 12. Giant colony of Mycoderma monosa sp. nov. on glucose agar. 
Plate 7

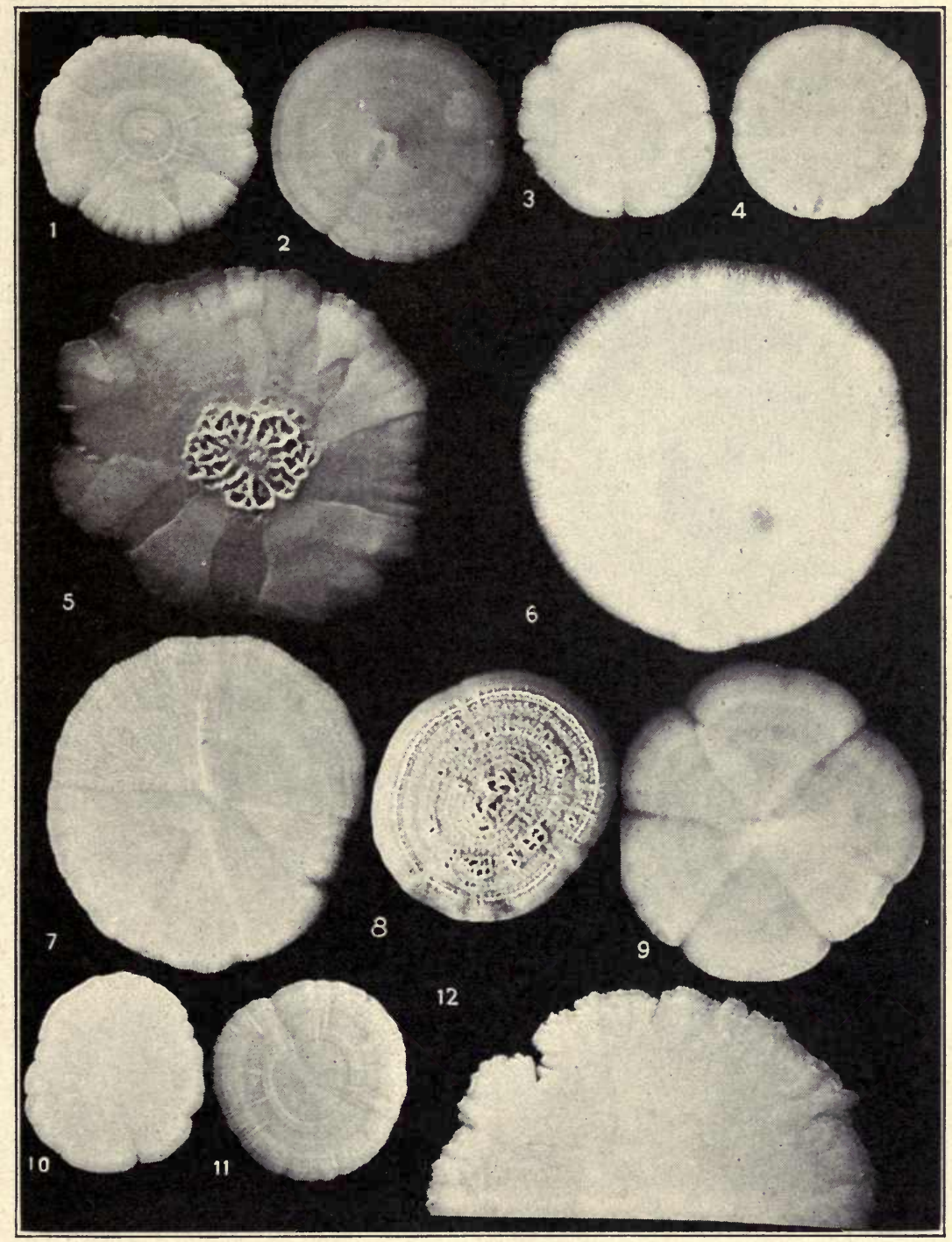


Frg. 1. Giant colony of Culture 231.102 on glucose agar.

FIG. 2. Giant colony of Culture 11.401 on glucose agar.

FIG. 3. Petri dish showing appearance of plate after inoculation from feces of person fed with yeasts. The white areas at points of contact are yeast colonies. The 4 indefinite light areas are colonies of Oidium lactis.

Fig. 4. Giant colony of Parasaccharomyces Ashfordi sp. nov. on glucose agar. (From Culture 2.501.) This photograph is taken from another series of cultures from that of Plate 5, Figure 8. The 2 colonies have many characters in common.

FIG. 5. Giant colony of Culture 129.101 on glucose agar. old.

FIg. 6. Giant colony of Oidium albicans on beerwort gelatin. One month

Fig. 7. Giant colony of Parasaccharomyces Ashfordi sp. nov. on beerwort gelatin. (From Culture 2.501.)

Fig. 8. Giant colony of Parasaccharomyces Ashfordi sp. nov. on beerwort gelatin. (From Culture D of Ashford.)

Fig. 9. Giant colony of Parasacchasomyces candida comb. nov. on beerwort gelatin. (From Culture 158.)*

FIg. 10. Giant colony of Mycoderma monosa sp. nov. on beerwort gelatin.

Fig. 11. Giant colony of Parasaccharomyces candida comb. nov. on beerwort gelatin. (From Culture 152.)

FIG. 12. Giant colony of Parasaccharomyces Thomasi sp. nov. on beerwort gelatin. *

FIG. 13. Giant colony of Culture 138.102 on beerwort gelatin.

Fig. 14. Giant colony of Cryptococcus verrucosus sp. nov. on beerwort gelatin.

FIG. 15. Giant colony of Culture 229.101 on beerwort gelatin. *

FIG. 16. Giant colony of Saccharomyces ellipsoideus Hansen on beerwort gelatin. *

FIG. 17. Giant colony of Culture 141.201 on beerwort gelatin.

Frg. 18. Giant colony of Pseudosaccharomyces Stevensi sp. nov. on beerwort gelatin.

FIG. 19. Giant colony of Cryptococcus aggregatus sp. nov. on beerwort gelatin.

Fig. 20. Giant colony of Cryptococcus ovoideus sp. nov. on beerwort gelatin.

FIG. 21. Giant colony of Cryptococcus glabratus sp. nov. on beerwort gelatin.

Fig. 22. Giant colony of Parasaccharomyces candida comb. nov. beerwort gelatin. (Culture from Centralstelle für Pilzkulturen.)

Frg. 23. Giant colony of Mycoderma rugosa sp. nov. on beerwort gelatin. (Culture 10 days old.) *

* Upside-down. 
Plate 8

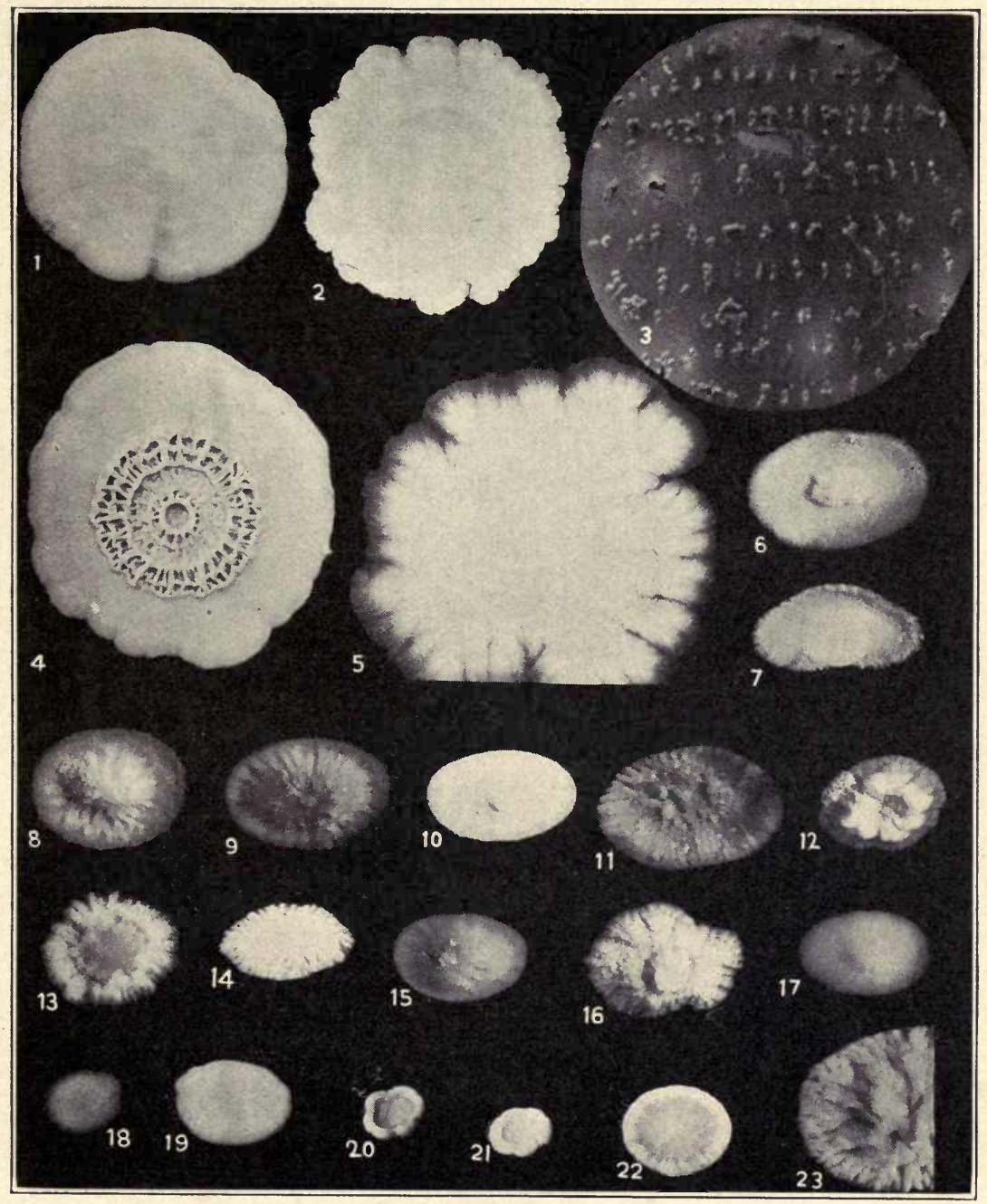





\section{BIOGRAPHICAL SKETCH}

Harry Warren Anderson was born at Ladoga, Indiana, on October, 14, 1885. After graduating from the local high school he entered Wabash College, receiving the degree of bache'or of arts in 1907. The fo!lowing year was spent as Teaching Fellow in Biology at Vanderbilt University. In the fa!l of 1908 he returned to Wabash College as Instructor in Botany and, after two years of graduate study in that institution, received the degree of master of arts. The academic year of 1910-11 was spent as Research Fellow in the Shaw Graduate School of Botany. At the end of that year he was e'ected to Sigma Xi in Washington University. In 1911 he was appointed Assistant in Floricultural Pathology in the Agricultural Experiment Station of the University of Illinois. The following March he accepted the position of Professor of Botany in Wabash College. A leave of absence for the year 1916-17 was granted in order to allow him to complete the necessary graduate work for his doctorate in the University of Illinois. J)uring this period he acted as Assistant in Botany in this University. 






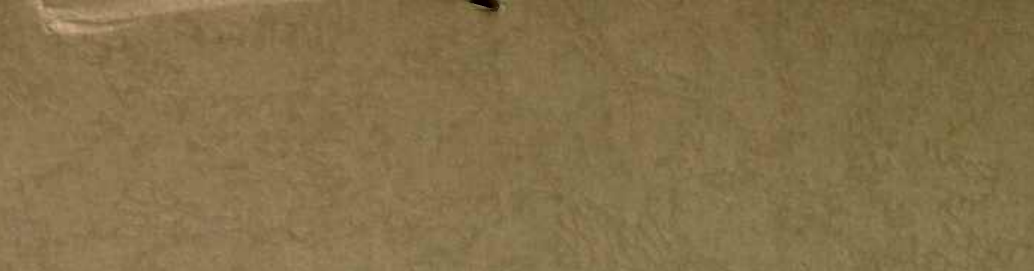

